\title{
Situation of antibiotic resistance in Bangladesh and its association with resistance genes for horizontal transfer
}

Kazi Sarjana Safain ${ }^{1,3 \pi}$, Golam Sarower Bhuyan ${ }^{1 \pi}$, Sadia Tasnim ${ }^{1,3 \pi}$, Saad Hassan Hasib ${ }^{1}$, Rosy Sultana ${ }^{1,4}$, Mohammad Sazzadul Islam ${ }^{2,7}$, Mohammad Al Mahmud-Un-Nabi ${ }^{1}$, Suprovath Kumar Sarker $^{2}$, Farjana Akther Noor ${ }^{2,10}$, Asifuzzaman Rahat ${ }^{1}$, Md Abdul Majid Bhuiyan $^{5}$, Md Tarikul $^{2}$ Islam² $^{2}$ Farhana Manzoor ${ }^{3}$, Sajid Anwar ${ }^{9}$, Daniel Leung ${ }^{8}$, Syed Saleheen Qadri ${ }^{1,2}$, Firdausi Qadri $^{1,2,6}$, Kaiissar Mannoor ${ }^{1,2 *}$

1 Infectious Diseases Laboratory, institute for developing Science and Health initiatives, Mohakhali, Dhaka, Bangladesh

2 Genetics and Genomics Laboratory, institute for developing Science and Health initiatives, Mohakhali, Dhaka, Bangladesh

${ }^{3}$ Department of Mathematics and Natural Sciences, BRAC University, Mohakhali, Dhaka, Bangladesh

${ }^{4}$ Department of Immunology, Bangladesh University of Health Sciences, Mirpur, Dhaka, Bangladesh

${ }^{5}$ BIHSH and UHC Component Institution, Bangladesh Institute of Health Sciences General Hospital, Mirpur, Dhaka, Bangladesh

${ }^{6}$ Department of Enteric and Respiratory Infectious Diseases, Infectious Diseases Division, International Centre for Diarrhoeal Disease Research, Bangladesh, Mohakhali, Dhaka, Bangladesh 
${ }^{7}$ Department of Biochemistry and Molecular Biology, Jagannath University, Dhaka, Bangladesh

${ }^{8}$ Division of Infectious Diseases, The University of Utah, Salt Lake City, United States

${ }^{9}$ Department of Genetic Engineering and Biotechnology, University of Dhaka, Dhaka, Bangladesh

${ }^{10}$ Department of Biochemistry and Molecular Biology, University of Dhaka, Dhaka, Bangladesh

*kaiissar@ideshi.org (KM)

If These authors contributed equally to this work 


\section{Abstract}

2 The study investigated the spectrum of antibiotic resistance and the associated genes for

3 aminoglycoside, macrolide and ESBL class of antibiotics using clinical isolates. A total of 430

4 preserved bacterial strains (Acinetobacter baumannii, $\mathrm{n}=20 ;$ Pseudomonas aeruginosa, $\mathrm{n}=26$;

5 Klebsiella pneumoniae, $\mathrm{n}=42 ;$ E.coli, $\mathrm{n}=85 ;$ Staphylococcus aureus, $\mathrm{n}=84 ;$ Salmonella Typhi,

$6 \mathrm{n}=82$; Enterococcus spp., $\mathrm{n}=27$; Streptococcus pneumoniae, $\mathrm{n}=36$ and CNS, $\mathrm{n}=28$ ) were

7 examined. The strains were isolated from patients admitted to various tertiary hospitals of Dhaka

8 city between 2015 and 2019 with either acute respiratory infections, wound infections, typhoid

9 fever or diarrhea. The isolates were reconfirmed by appropriate microbiological and biochemical methods. Antimicrobial susceptibility tests were done using Kirby-Bauer disk diffusion approach.

11 PCR amplification using resistance gene-specific primers for aminoglycoside, macrolide and

12 ESBL class of antibiotics was done and the amplified products were confirmed by Sanger

13 sequencing. Of the total isolates, 53\% came out as MDR with $96.6 \%$ of $\quad$ E. coli and $90 \%$ of

14 Staphylococcus aureus. There was a year-wise gradual increase of MDR isolates from 2015-2018

15 and by 2019 the increase in MDR isolates became almost 2-fold compared to 2015. Among the

16 five ESBL genes investigated, CTXM-1 came out as the most prevalent (63\%) followed by NDM-

$171(22 \%)$ and $E$. coli isolates were the predominant reservoir of these genes. ErmB (55\%) was the

18 most frequently detected macrolide resistance gene, whereas aac(6)-Ib $(35.44 \%)$ was the most

19 prevalent aminoglycoside resistance gene and these genes were most prevalent in E. coli and $P$.

20 aeruginosa isolates, respectively. CTXM-1 and ErmB (16.66\%) were the most frequent partners

21 of coexistence followed by CTXM-1 and aac(3)-II. 


\section{Introduction}

24 Antimicrobial resistance (AMR) is becoming a very challenging problem worldwide. Solving the AMR problem should be the priority of global efforts. Nosocomial infections have been recognized as the hub for thriving multidrug resistant (MDR) pathogens. It is estimated that around $8.7 \%$ of the hospitalized patients worldwide develop nosocomial infections which is the leading cause of surgical failure, transplant rejection, treatment failure, increased costs and even deaths [1]. Numerous reports suggest that absolute numbers of infections due to resistant microbes are increasing globally [2-4]. It is conservatively estimated that at least 2 million illnesses and 23,000 deaths had been caused by antibiotic resistant organisms per year in the USA [5]. The present trend predicts that infections by resistant bacterial pathogens may cause up to 10 million deaths/year more than any other causes - by 2050 and like the most global issues, the problem is inequitably distributed, with approximately $90 \%$ of the predicted deaths are estimated to happen in Asia and Africa [6]. Additionally, treatment of the patients infected with resistant pathogens is associated with higher costs, requiring additional investigations and longer hospitalization [7]. The overall crude economic burden of antibiotic resistance was estimated to be at least $€ 1.5$ billion in 2007 in Europe and \$55 billion in 2000 in the USA, including patients and hospital costs [8]. Without appropriate action, by 2050 the global economy may lose more than USD 6 trillion annually because of AMR, which is nearly 4\% of Gross Domestic Product (GDP) [7].

41 Studies show that low-income countries like Bangladesh are more affected by AMR because of

42 the widespread misuse of antibiotics, non-human antibiotic use, poor quality of drugs, inadequate surveillance and factors associated with individual and national poverty indicators like poor 44 healthcare standards, malnutrition, chronic and repeated infections, unaffordability of more 
45 effective and costly drugs [9, 10]. Research regarding antibiotic resistance epidemiology may ultimately guide to interventions for AMR.

47 Regional surveillance programs have tracked antibiotic resistance in several countries, but still many gaps exist in some middle and low income countries that prohibit comprehensive monitoring and analysis of the prevalence and trends of resistance worldwide to appropriately guide interventions [11]. Thus, a well-functioning national AMR surveillance system is vital in planning and implementing the national AMR strategy. Studies on antimicrobial resistance encompassing

52 different aspects on a national scale are critical because they provide information on the extent of established resistance rates, as well as emerging patterns of resistance. Understanding how resistance is changing over time is important for (1) establishing prescribing guidelines, (2) determining investment in new therapies, and (3) improving the targeting of campaigns to reduce antimicrobial resistance. It also provides a baseline for future analysis and comparison with other

57 countries [12]. Studying resistance genes that cause antibiotic resistance and the plasmids that transfer such resistance genes, and other mechanisms that lead to antibiotic resistance will help to 59 generate new ideas, which in turn may lead to control the spread of resistance by targeting the resistance genes.

61 Previous studies on antibiotic resistance in Bangladesh have largely focused on Gram-negative

62 bacteria [13-15], and a limited number of antibiotic resistance genes [16-18]. The present study

63 was undertaken to investigate the contemporary antibiotic resistance patterns in Bangladesh,

64 including that of Gram-positive bacteria, which have emerged as global threats in serious 65 infections like pneumonia, wound infections and diabetic ulcer [19-21]. So, the study of antibiotic resistance to Gram-positive clinical isolates is by no means less important. In addition to antibiotic

67 resistance patterns of Gram-positive and Gram-negative bacteria, the study also investigated the 
68 genetic basis of resistance by analyzing previously reported resistance genes and a set of other

69 genes that had not been investigated in previous studies in Bangladesh, such as aac(6)-Ib, aac(3)-

70 II, aph(3)-VI, ant(3)-I, and ErmF genes. A comparative analysis of co-presence of resistance genes

71 was also done to know the importance of the presence of multiple genes in the horizontal spread

72 of antibiotic resistance for Gram-negative and Gram-positive bacteria. To know how alarmingly

73 the resistance was increasing with the passage of time, the kinetics of the rate of increase of

74 multidrug resistant (MDR) pathogens was determined between 2015 and 2019. 


\section{Materials and Method}

76 The present prospective study was carried out in the institute for developing Science and Health

77 initiatives (ideSHi), Dhaka, Bangladesh.

\section{$78 \quad$ Bacterial isolates}

79 The study analysed a total of 430 preserved bacterial isolates. These isolates were collected from

80 hospitalized patients with acute respiratory infections (nasopharyngeal swab), wound infections

81 (wound swab), typhoid fever (blood samples) and diarrhoeal diseases (stool samples) between

822015 and 2019 . The strains were preserved at $-70^{\circ} \mathrm{C}$ as glycerol stock. Bacterial identification and

83

84

85

86

87

88

89

90

91

92

reconfirmation were performed by routine conventional microbial cultures and biochemical tests using standard recommended techniques [22].

\section{Antimicrobial susceptibility testing}

Profiling of antimicrobial susceptibility/resistance was performed by the modified Kirby-Bauer disc diffusion method and the bacterial strains were identified as either sensitive or resistant to an antibiotic based on the diameter of inhibition zone interpretative chart, published in the Clinical and Laboratory Standard Institute (CLSI) guidelines, 2016. MDR strains were identified as resistant to three or more antimicrobial classes [23].

The cartridges of antimicrobial disks for Nalidixic acid, Cotrimoxazole, Amoxiclav, Ciprofloxacin, Azithromycin, Ampicillin, Cefixime, Gentamycin, Chloramphenicol, Meropenem, Ceftriaxone, Imipenem, Piperacillin-tazobactam, Norfloxacin, Tobramycin, Amikacin, Netilmicin, Carbenicillin, Tetracycline, Erythromycin, Levofloxacin, Doxycycline, Streptomycin, 
Trimethoprim-sulfamethoxazole, Polymyxin B, Rifampicin, Cefoxitin, Penicillin, Vancomycin,

97

98

99

100

101

102

103

104

105

106

107

108

109

110

111

112

113

114

115

116

117

118

Linezolid, and Clindamycin were obtained from Oxoid (Hampshire, UK). The cartridges were stored between $4{ }^{\circ} \mathrm{C}$ and $20^{\circ} \mathrm{C}$ and allowed to come to room temperature prior to use. After inoculation with the isolates and placement of the disks, Mueller-Hinton agar plates were incubated at $37^{\circ} \mathrm{C}$ for 24 hours and the zones of inhibition were measured.

\section{Determination of MAR index}

Multiple antibiotic resistance index (MAR) is broadly helpful in analyzing potential risk, and is used to determine the severity of antibiotic resistance [24]. In this study, antibiotics were used according to CLSI guideline for a particular species. MAR value was defined as $a / b$, where a represents the number of antibiotics to which the isolate was resistant, and b represents the number of antibiotics to which the isolate was exposed.

\section{PCR amplifications and sequencing}

Bacterial DNA was extracted from the isolated bacterial colonies by boiling method [25]. All the isolates were examined for the presence of resistance genes for different classes of antibiotics, namely aminoglycoside, macrolide and $\beta$-lactam. The gene sequences were retrieved from the nucleotide database of National Centre for Biotechnology Information (NCBI). The retrieved FASTA sequences were then used to design gene-specific primers using NCBI PrimerBLAST. The following sets of primers were used for each resistance gene: (1) aac(3)-II: F1: 5'ATATCGCGATGCATACGCGG-3', R1: 5'-GACGGCCTCTAACCGGAAGG-3'; (2) aac(6)-Ib: F2: 5'-TTGCGATGCTCTATGAGTGGCTA-3'， R2： 5'-R1CTCGAATGCCTGGCGTGTTT-3'; (3) aac(6)-II: F3: 5'-CGACCATTTCATGTCC-3'，R3：5'-GAAGGCTTGTCGTGTTT-3'; (4) 
ant(3)-I: F4: 5'-CATCATGAGGGAAGCGGTG-3'，R4: 5'-GACTACCTTGGTGATCTCG-3';

$\operatorname{aph}(3)-V I$ :

F5:

5'-ATGGAATTGCCCAATATTATT-3',

R5:

$5^{\prime}-$ 5'-GAAAATGAGTGCCTTGGAGG-3'; (7) rmtB: F7: 5'-ATGAACATCAACGATGCCCTC-3', R7: $\quad$ 5'-CCTTCTGATTGGCTTATCCA-3';

$\operatorname{ErmA:}$

F8: $\quad 5^{\prime}-$

CTTCGATAGTTTATTAATATTAGT-3'， R8： 5'-TCTAAAAAGCATGTAAAAGAA-3';

ErmB: F9: 5'-GGAACATCTGTGGTATGGCG-3', R9: 5'-CATTTAACGACGAAACTGGC-3';

ErmC:

F10:

5'-CAAACCCGTATTCCACGATT-3',

R10: $\quad 5^{\prime}-$

ATCTTTGAAATCGGCTCAGG-3'; (11) ErmF: F11: 5'-TGTTCAAGTTGTCGGTTGTG-3',

R11: $\quad$ 5'-CAGGACCTACCTCATAGACA-3';

$K P C:$

F12: $\quad 5^{\prime}-$

CTGTCTTGTCTCTCATGGCC-3'， R12： 5'-CCTCGCTGTGCTTGTCATCC-3'; (13) Oxa48: F13: 5'-GCGTGGTTAAGGATGAACAC-3', R13: 5'-CATCAAGTTCAACCCAACCG-3'; (14) VIM1: F14: 5'-AGTGGTGAGTATCCGACAG-3'，R14： 5'-ATGAAAGTGCGTGGAGAC-3';

NDM-1:

F15:

5'-GGTTTGGCGATCTGGTTTTC-3',

R15:

5'CGGAATGGCTCATCACGATC-3';

CTX-M1:

F16:

5'AATCACTGCGCCAGTTCACGCT-3'， R16: 5'-AGCCGCCGACGCTAATACA-3'. Genespecific PCR amplification using each set of primers was carried out on a T100 TM thermal cycler (Bio-Rad, USA). The PCR reaction volume was $10 \mu \mathrm{L}$ containing $1 \mu \mathrm{L} 10 \mathrm{X}$ PCR buffer, $0.3 \mu \mathrm{L}$ $50 \mathrm{mM} \mathrm{MgCl}_{2}, 0.2 \mu \mathrm{L}$ of $10 \mathrm{mM}$ dNTPs mixture, $0.5 \mu \mathrm{L}$ forward and reverse primers, $0.05 \mu \mathrm{L}$ of Taq polymerase, $5.45 \mu \mathrm{L}$ Nuclease Free Water and $2 \mu \mathrm{L}$ of template DNA. The following cycling conditions were used: initial denaturation at $95^{\circ} \mathrm{C}$ for 5 minutes, 35 cycles of denaturation at $95^{\circ} \mathrm{C}$ for 30 seconds, annealing at $55^{\circ} \mathrm{C}$, cyclic extension at $72^{\circ} \mathrm{C}$ for 45 seconds, and final extension at $72^{\circ} \mathrm{C}$ for 6 minutes. The amplified PCR products were visualized on a $1 \%$ agarose gel stained with 
142 SYBR Safe (Invitrogen, USA) staining. Later, the PCR products were purified using Quick PCR

143 product purification kit (Invitrogen, USA) following the manufacturer's guidelines.

145 Sanger DNA sequencing

146 The PCR-amplified DNA was sequenced using ABI PRISM-310 software version 3.1.0

147 (Applied Biosystems). To prepare cycle sequencing reaction mixtures, $1 \mathrm{ng}$ of purified DNA was

148 added to a reaction solution containing $0.50 \mu \mathrm{L}$ Big dye terminator sequencing mix and $2.0 \mu \mathrm{L}$ of

149 5X PCR sequencing buffer with $0.2 \mu \mathrm{L}$ primer solution. Then, the PCR strip was placed in the

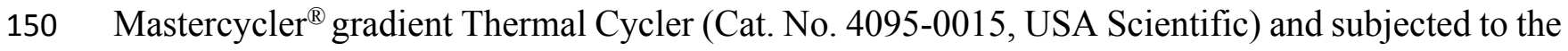

151 following thermal cycling profile: pre-denaturation at $95^{\circ} \mathrm{C}$ for 10 minutes; 25 cycles of

152 denaturation at $95^{\circ} \mathrm{C}$ for 10 seconds, annealing at $55^{\circ} \mathrm{C}$ for 5 seconds, cyclic extension at $72^{\circ} \mathrm{C}$ for

1534 minutes; and a final extension at $72^{\circ} \mathrm{C}$ for 6 minutes.

154

155 Data analysis

156 Sequencing data were analysed by Chromas Lite 2.4 software to identify the target sequence by

157 alignment with reference sequence. The obtained sequence was subjected to further analysis using

158 Basic Local Alignment Search Tool (BLAST) for finding sequence similarity with sequences

159 already reported in online databases. Graphs were generated using GraphPad Prism 7.00 software.

160

161 


\section{Results}

\section{Selection of clinical isolates}

The study analyzed a total of 430 preserved $\left(-80^{\circ} \mathrm{C}\right)$ clinical bacterial isolates from patients with acute respiratory infections $(n=40)$, wound infections $(n=239)$, typhoid $(n=82)$ and diarrhea

167 ( $n=69)$. Among the enlisted 12 global priority pathogens (GPP) according to World Health

168 Organization (WHO), the present study worked on 8 bacterial species from GPP list including

169 Acinetobacter baumannii $(\mathrm{n}=20)$, Pseudomonas aeruginosa $(\mathrm{n}=26)$, Klebsiella pneumoniae

$170(\mathrm{n}=42)$ and Escherichia coli $(\mathrm{n}=85)$ as the Priority 1 (Critical) pathogens, followed by

171 Staphylococcus aureus $(\mathrm{n}=84)$, Salmonella Typhi $(\mathrm{n}=82)$ and Enterococcus $\mathrm{spp} .(\mathrm{n}=27)$ as the

172 Priority 2 (High) pathogens. Among the Priority 3 (Medium) pathogens list, Streptococcus

173 pneumoniae $(\mathrm{n}=36)$ isolates were analyzed. Additionally, CNS $(\mathrm{n}=28)$ which is not enlisted in any

174 of the priority list, was also investigated. These clinical specimens were collected from patients

175 admitted to various tertiary hospitals of Dhaka city between 2015 and 2019 (Table 1).

Table 1. Information of clinical isolates analyzed.

\begin{tabular}{|c|c|c|c|c|c|c|c|c|c|}
\hline $\begin{array}{l}\text { Clinical } \\
\text { isolates }\end{array}$ & $\begin{array}{l}\text { Pseudomonas } \\
\text { aeruginosa }\end{array}$ & $\begin{array}{l}\text { Klebsiella } \\
\text { pneumoniae }\end{array}$ & $\begin{array}{l}\text { Acinetobacter } \\
\text { baumannii }\end{array}$ & $\begin{array}{l}\text { Escherichia } \\
\text { coli }\end{array}$ & $\begin{array}{l}\text { Salmonella } \\
\text { Typhi }\end{array}$ & $\begin{array}{l}\text { Enterococcus } \\
\text { spp. }\end{array}$ & $\begin{array}{l}\text { Staphylococcus } \\
\text { aureus }\end{array}$ & $\begin{array}{l}\text { Streptococcus } \\
\text { pneumoniae }\end{array}$ & CNS \\
\hline $\begin{array}{l}\text { Typhoid } \\
(n=82)\end{array}$ & & & & & 82 & & & & \\
\hline $\begin{array}{l}\text { Diarrhea } \\
(n=69)\end{array}$ & & & & 69 & & & & & \\
\hline $\begin{array}{l}\text { Wound } \\
\text { infection } \\
(n=239)\end{array}$ & 26 & 30 & 20 & 12 & & 17 & 84 & 12 & 28 \\
\hline $\begin{array}{l}\text { Acute } \\
\text { respiratory }\end{array}$ & & 12 & & 4 & & & & 24 & \\
\hline
\end{tabular}




\begin{tabular}{|c|c|c|c|c|c|c|c|c|c|}
\hline $\begin{array}{l}\text { infection } \\
(n=40)\end{array}$ & & & & & & & & & \\
\hline $\begin{array}{l}\text { Total }(n= \\
430)\end{array}$ & Total $(\mathrm{n}=26)$ & $\begin{array}{l}\text { Total }(\mathrm{n}= \\
42)\end{array}$ & Total $(\mathrm{n}=20)$ & $\begin{array}{l}\text { Total }(\mathrm{n}= \\
85)\end{array}$ & $\begin{array}{l}\text { Total }(\mathrm{n}= \\
82)\end{array}$ & Total $(\mathrm{n}=27)$ & Total $(\mathrm{n}=84)$ & Total $(\mathrm{n}=36)$ & $\begin{array}{l}\text { Total } \\
(\mathrm{n}= \\
28)\end{array}$ \\
\hline
\end{tabular}

179

\section{Antibiotic susceptibility/resistance patterns for the isolated bacterial strains}

Next, we wanted to see the antibiotic resistance pattern of the isolated Gram-negative (Figs 1A1E) and Gram-positive (Figs $1 \mathrm{~F}-1 \mathrm{~J}$ ) bacterial isolates. To interpret the data, the median value of the resistance rate of each of the isolates was calculated and the data were analyzed. In Fig 1(A), we see that $S$. Typhi, which is the major causative agent for typhoid, was found to be $89 \%$ resistant to nalidixic acid. However, 10 out of 19 antibiotics showed complete sensitivity to $S$. Typhi. Moreover, $P$. aeruginosa and $K$. pneumoniae isolates exhibited an elevated resistance to almost all the antibiotics tested. Overall, $P$. aeruginosa showed the highest resistance to majority of the antibiotics investigated. For P. aeruginosa, 15 antibiotics were tested and all of these antibiotics exhibited resistance at different degrees and 7 of these antibiotics including imipenem (45\%), ciprofloxacin (59\%), tobramycin (78\%), gentamycin (67\%), amikacin (45\%), netilmicin (45\%) and carbenicillin (48\%) showed higher resistance rates than the median (41\%) (Fig 1B). Next, 7 out of 18 antibiotics tested (ceftriaxone, ciprofloxacin, azithromycin, cefixime, tobramycin, ampicillin and gentamycin) against $K$. pneumoniae crossed the median (22\%) with resistance rates of $40 \%, 47 \%, 58 \%, 66 \%, 42 \%, 33 \%$ and $42 \%$, respectively (Fig 1C). For Gram-positive bacteria, although there were antibiotics which exhibited enough efficacy against $S$. aureus such as vancomycin (4\% resistance) and chloramphenicol (3\% resistance), still 8 out of 16 antibiotics 
crossed the median (24\%) and 4 antibiotics, namely cefixime, cefoxitin, erythromycin, and penicillin had more than $50 \%$ resistance. In addition, $84 \% \mathrm{~S}$. aureus isolates were found to be MRSA (Methicillin Resistant $S$. aureus) as these $S$. aureus strains were resistant to cefoxitin (Fig 1F). For CNS, 7 out of 18 antibiotics including ciprofloxacin, rifampicin, cefoxitin, erythromycin, penicillin, levofloxacin and clindamycin crossed the median (33\%) with resistance rates of $38 \%$, $38 \%, 41 \%, 58 \%, 66 \%, 38 \%$ and 38\%, respectively (Fig 1G). Overall, the data reveal that although there were 1 or more antibiotics which showed complete sensitivity against S. Typhi, E. coli, A. baumannii, Enterococcus spp. and S. pneumoniae, majority of the tested antibiotics showed resistance from moderate to extremely higher degrees against these organisms. On the contrary, P. aeruginosa, $K$. pneumoniae, $S$. aureus, and CNS isolates showed resistance to all of the tested antibiotics with different degrees and even many of these bacterial isolates exhibited more than $50 \%$ resistance, which may indicate an alarming and deteriorating situation for antibiotic use. Colistin resistance was detected in $10 \% \quad K$. pneumoniae and $11 \%$ P. aeruginosa. Finally, like Gram-negative bacteria, Gram-positive bacteria had equally raised resistance against different antimicrobials.

\section{Fig 1. Rates of resistance of the isolated organisms to different antibiotics. Kirby Bauer disk} diffusion method was applied to determine resistance/sensitivity rate of each isolate. A. Salmonella Typhi, B. Pseudomonas aeruginosa, C. Klebsiella pneumoniae, D. E. coli, E. Acinetobacter baumannii, F. Staphylococcus aureus, G. CNS, H. Enterococcus spp., I. Streptococcus pneumoniae. Abbreviation expansion for antibiotics used: NA= Nalidixic acid, COT= Cotrimoxazole, $\mathrm{AMO}=$ Amoxiclav, $\mathrm{CIP}=$ Ciprofloxacin, $\mathrm{AZM}=$ Azithromycin, $\mathrm{AMP}=$ Ampicillin, $\mathrm{CFM}=$ Cefixime, $\mathrm{CN}=$ Gentamycin, $\mathrm{C}=$ Chloramphenicol, $\mathrm{MEM}=$ Meropenem, 
$\mathrm{CRO}=$ Ceftriaxone, $\mathrm{IMP}=$ Imipenem, $\mathrm{CL}=$ Colistin, $\mathrm{TZP}=$ Piperacillin-tazobactam, NOR= Norfloxacin, $\mathrm{TOB}=$ Tobramycin, $\mathrm{AK}=$ Amikacin, $\mathrm{NET}=$ Netilmicin, $\mathrm{CAR}=$ Carbenicillin, $\mathrm{TE}=$ Tetracycline, E= Erythromycin, $\mathrm{LEV}=$ Levofloxacin, $\mathrm{DO}=$ Doxycycline, $\mathrm{S}=$ Streptomycin, $\mathrm{SXT}=$

224 Trimethoprim-sulfamethoxazole, $\mathrm{PB}=$ Polymyxin $\mathrm{B}, \mathrm{RIF}=$ Rifampicin, $\mathrm{FOX}=$ Cefoxitin, $\mathrm{P}=$ 225 Penicillin, $\mathrm{VAN}=$ Vancomycin, $\mathrm{LZ}=$ Linezolid, $\mathrm{CD}=$ Clindamycin.

\section{Antibiotic resistance profile and MAR index}

Table 2 shows the antibiotic resistance profile and Multiple Antibiotic Resistance (MAR) index of the indicated isolates. The proportion of the isolates with MAR index $>0.2$ was $53.73 \%$; while those with MAR index $\leq 0.2$ was $43.25 \%$ and the findings indicate that more than $50 \%$ of the isolates were likely to be from high risk sources. A large proportion of $P$. aeruginosa $(80.77 \%), S$. aureus $(78.57 \%)$ and $K$. pneumoniae $(76.2 \%)$ isolates exhibited MAR index value of $>0.2$, whereas the highest mean value of MAR index $(0.562 \pm 18)$ was observed for P. aeruginosa.

Table 2. Distribution of Multiple Antibiotic Resistance (MAR) indices within the identified organisms.

\begin{tabular}{|c|c|c|c|c|c|c|c|c|c|c|}
\hline $\begin{array}{l}\text { MAR } \\
\text { Index } \\
\text { (Range) }\end{array}$ & $\begin{array}{c}\text { S. Typhi, } \\
n(\%)\end{array}$ & $\begin{array}{c}P . \\
\text { aeruginosa } \\
n(\%)\end{array}$ & $\begin{array}{c}K . \\
\text { pneumoniae } \\
n(\%)\end{array}$ & $\begin{array}{l}\text { E. coli } \\
n(\%)\end{array}$ & $\begin{array}{c}A . \\
\text { baumannii } \\
n(\%)\end{array}$ & $\begin{array}{l}\text { CNS } \\
n(\%)\end{array}$ & $\begin{array}{l}E . \text { spp } \\
n(\%)\end{array}$ & $\begin{array}{c}\text { S. aureus } \\
n(\%)\end{array}$ & $\begin{array}{c}S . \\
\text { pneumoniae } \\
n(\%)\end{array}$ & $\begin{array}{l}\text { Total } \\
n(\%)\end{array}$ \\
\hline$<0.2$ & $52(63.42)$ & $5(19.23)$ & $10(23.8)$ & $56(65.89)$ & $9(45)$ & $9(32.14)$ & $13(48.15)$ & $14(17.86)$ & $17(47.22)$ & $186(43.25)$ \\
\hline 0.2 & 0 & 0 & 0 & 0 & 0 & $3(10.75)$ & 0 & $3(3.57)$ & $7(19.44)$ & $13(3.02)$ \\
\hline $\begin{array}{c}>0.2 \\
\operatorname{Mean} \pm \text { SD }\end{array}$ & $\begin{array}{c}30(36.58) \\
0.34 \pm 0.108\end{array}$ & $\begin{array}{c}21(80.77) \\
0.562 \pm \\
0.18\end{array}$ & $\begin{array}{c}32(76.2) \\
0.38 \pm 0.15\end{array}$ & $\begin{array}{c}29(34.11) \\
0.32 \pm \\
0.133\end{array}$ & $\begin{array}{l}11(55) \\
0.312 \pm \\
0.089\end{array}$ & $\begin{array}{c}16 \\
(57.11) \\
0.45 \pm \\
0.11\end{array}$ & $\begin{array}{c}14(51.85) \\
0.38 \pm \\
0.14\end{array}$ & $\begin{array}{l}66(78.57) \\
0.4 \pm 0.11\end{array}$ & $\begin{array}{c}12(33.34) \\
0.34 \pm 0.059\end{array}$ & $231(53.73)$ \\
\hline Total & 82 & 26 & 42 & 85 & 20 & 28 & 27 & 84 & 36 & 430 \\
\hline
\end{tabular}




\section{Frequencies of MDR isolates}

239

240

241

242

243

244

245

246

247

248

249

250

251

252

253

254

255

256

257

258

Fig 2. Resistance frequency of the indicated clinical isolates. (A) MDR frequencies of the indicated organisms. (B) Proportion of the mentioned bacterial isolates which were resistant to the indicated numbers of drugs. By \% MDR in Fig A, we mean \% isolates showing resistance to more than 3 antibiotic classes among total isolates of a bacterial species and each color here indicates a bacterial species. For Fig B, each color indicates the number of antibiotics to which a bacterial species was resistant.

To evaluate the extent of multidrug resistance, the percentage of resistance for each bacterial species was assessed. Approximately, 53\% isolates were identified as MDR. Fig 2A shows that $E$. coli $(96.6 \%)$ was found to be the most prevalent MDR organism, followed by $S$. aureus (90\%), $P$. aeruginosa (83.4\%), K. pneumoniae (80.69\%), CNS (75.5\%), S. aureus (75\%), A. baumannii (66.67\%), Enterococcus spp. (60.42\%), S. pneumoniae (55.62\%) and S. Typhi (34.7\%). Next, in Fig 2(B), we see that resistance with more than 6 antibiotics was found to be $68 \%$ for $S$. aureus, followed by $62.5 \%$ for $P$. aeruginosa and $5 \%$ for CNS. The resistance rates for $2,3,4,5,6$, and $>6$ antibiotics were $3.4 \%, 10.22 \%, 28.4 \%, 22.72 \%, 11.4 \%$ and $23.86 \%$, respectively among the $E$. coli isolates. Among $P$. aeruginosa and $K$. pneumoniae, only $2 \%$ isolates exhibited $100 \%$ sensitivity. The resistance rates for $1,2,3,4,5,6$, and $>6$ antibiotics were $6.3 \%, 8.3 \%, 0 \%, 8.3 \%$, $8.3 \%, 4.3 \%$ and $62.5 \%$, respectively for the $P$. aeruginosa isolates, whereas the corresponding resistance rates for $K$. pneumoniae were $10 \%, 7.31 \%, 2.41 \%, 17 \%, 9.75 \%, 12.53 \%$ and $39 \%$. On the other hand, $1 \%, 2 \%, 1.6 \%, 0.4 \%, 5 \%, 21 \%$ and $68 \% S$. aureus isolates were found to be 
resistant to $1,2,3,4,5,6$, and $>6$ antibiotics, respectively. So, the data indicates that antibiotic resistance levels have reached alarmingly high levels for $S$. aureus, $P$. aeruginosa, K. pneumoniae and E. coli, although $S$. Typhi and $S$. pneumoniae isolates had shown susceptibility to most of the antibiotics tested and none of the isolates was resistant to $>6$ antibiotics.

\section{Resistance gene profiles among the tested isolates}

Fig 3. Distribution of CTXM-1, NDM-1, OXA-48, ErmB, ErmF, ErmC, aac(6)-Ib, aac(3)-II, $\operatorname{aph(3)-VI,~armA~and~ant-3I~genes~among~the~indicated~isolates.~In~the~Figure,~PSA=~}$ Pseudomonas aeruginosa, $\mathrm{SPN}=$ Streptococcus pneumoniae, $\mathrm{KPN}=$ Klebsiella pneumoniae, $\mathrm{EC}=$ Escherichia coli, STA=Staphylococcus aureus, STY= Salmonella Typhi, ACB=Acinetobacter baumannii, ENS=Enterococcus spp.

To observe the resistance gene spectrum among different bacterial isolates, the percentages of antibiotic resistance genes were assessed. Fig 3 shows that E. coli strains had harbored all of the resistance genes analyzed except aph(3)-VI. S. aureus, K. pneumoniae and $P$. aeruginosa were detected as the next prevalent organisms which had higher percentages of resistance genes, in particular CTXM-1, ErmB, aac(6)-Ib and aac(3)-II. The most frequently identified ESBL gene was CTXM-1 (Amber class-A type) and it was detected in almost every species of bacteria with the highest frequencies found in S. aureus (36\%), followed by K. pneumoniae (30\%) and E. coli (28\%). However, none of the S. Typhi and CNS strains showed to harbor this gene. NDM-1, which is a metallo- $\beta$-lactamase of Amber class-B was also shown to be commonly detected among ESBL 
genes. The predominant bacterial species which harbored this gene was found to be K. pneumoniae

282 (19\%). Among the Amber class-D type ESBL genes, OXA-48 was predominantly present in

14.75\% S. aureus strains. The commonly detected macrolide resistance gene, ErmB was detected

in $24.50 \%$ E. coli, $19 \%$ K. pneumoniae and 16\% P. aeruginosa. In addition, $30 \%$ P. aeruginosa

and $11 \%$ CNS were found to possess aac(6)-Ib gene, which is the frequently detected

aminoglycoside resistance gene. S. pneumoniae, S. Typhi and Enterococcus spp. were found to

287 harbor only 2 of the investigated resistance genes, with ErmB being the commonly harbored

288 resistance gene.

\section{Phenotypic discrepancies}

Fig 4. Existing inconsistencies among the isolated organisms. The orange bar indicates the

organisms having their resistance genes detected and these organisms gave positive results on disk diffusion analysis, whereas the brown bar indicates those organisms having their resistance genes detected but the disk diffusion results were negative. On the other hand, the green bar indicates organisms for which no resistance genes were detected but they showed resistance on disk

297 diffusion analysis, while the blue bar indicates those isolates which gave negative results in terms 298 of both gene detection and antibiogram results.

The antibiotic-resistant determinants associated with resistance were detected by PCR and subsequently confirmed by Sanger sequencing. Of the 430 isolates tested, 115 (27\%) isolates did 
(the green bar of Fig 4). On the contrary, $10(2.33 \%)$ of the total isolates encompassing all bacterial species were observed to be phenotypically inconsistent although these isolates harbored resistance genes. The rest of the isolates $(n=305)$ had matching consistency in terms of genotypes and phenotypes.

\section{Comparison of the year-wise rate of resistance genes and MDR isolates}

Fig 5. Kinetics of the spread of MDR organisms along with antibiotic resistance genes upon passage of time. (A) Comparison of the percentages of the organisms carrying antibiotic resistance genes over five years, (B) Comparison of the rate of sums of the MDR organisms (resistant to more than 3 antibiotic classes) that included PSA, SPN, KPN, EC, STA, STY, CNS, ACB, ENS isolates between 2015 and 2019. For both Fig A and Fig B, the number of samples analyzed were 92, 82, 63, 85 and 108 for 2015, 2016, 2017, 2018 and 2019, respectively. Each color in Fig A indicates an antibiotic resistance gene.

To observe the antibiotic resistance trend of the pathogenic organisms enlisted in the WHO priority list, the year-wise percentages of MDR organisms along with the resistance genes were compared between 2015 and 2019. Fig 5A shows that the percentages of organisms harboring CTXM-1, ErmB, aac(6)-Ib, NDM-1, and aac(3)-II resistance genes were 14, 17, 22, 3, and 3 for 2015 specimens, whereas the presence of these resistance genes increased to $44 \%, 35 \%, 28 \%, 16 \%$, and $29 \%$, respectively for specimens of 2019 . On the other hand, although the resistance genes, namely 
appeared in $10 \%, 2 \%, 10 \%, 5 \%$, and $3 \%$ of the tested organisms of 2019 . Next, Fig 5B shows that MDR organisms were gradually increasing with the passage of time. There were $33 \%(n=30)$ MDR organisms in 2015 and they increased gradually in 2016, 2017, and 2018 and became 62\% $(n=67)$ in 2019. That is, the proportion of MDR organisms has become almost double in 2019 compared to the 2015. Overall, the data reveal that rates of MDR organism along with resistance genes are in an alarmingly increasing trend with the passage of time.

\section{Co-existence of multiple antibiotic resistance genes in the tested isolates}

Next, we wanted to investigate co-presence of resistance genes. The results of co-presence of resistance genes are displayed in Table 3 . Out of 430 strains, a total of 102 strains revealed to possess co-presence of resistance genes. . coli $(\mathrm{n}=40), P$. aeruginosa $(\mathrm{n}=26)$ and $S$. aureus $(\mathrm{n}=17)$ strains were found to be the predominant organisms in harboring the co-resistance genes. In the 85 E. coli isolates analyzed, co-existence of (a) CTXM-1 and ErmB (n=10) was identified as the most prevalent combination, followed by (b) CTXM-1 and aac(3)-II (n=5), (c) ErmB and ErmC (n=4), (d) CTXM-1 and ErmC (n=3), CTXM-1 and ErmF (n=3), ErmB and ErmF (n=3), (e) CTXM-1 and aac(6)-Ib (n=2) and NDM-1and aac(3)-II $(\mathrm{n}=2)$. Alarming enough to know that an E. coli isolate showed to possess a set of five genes, namely ErmB, ErmF, aac(6)-Ib, ant(3)-I and CTXM1. On the other hand, all $26(100 \%)$ P. aeruginosa isolates that had been analyzed showed copresence of resistance genes in different combinations. A P. aeruginosa isolate was seen to contain multiple ESBL genes (CTXM-1, NDM-1 and OXA-48), with the addition of aac(6)-Ib, an aminoglycoside resistance gene. Overall, the data demonstrate that $P$. aeruginosa has a common phenomenon (100\%) of harboring multiple resistance genes, whereas $47 \%$ of $E$. coli, $32 \%$ of $K$. 
pneumoniae, and $20 \%$ of $S$. aureus isolates harbored multiple genes. The rest of the bacterial species had relatively low presence of multiple genes (Table 3). S. Typhi, S. pneumoniae, and Enterococcus spp. did not have co-presence of any of the tested genes (data not shown). Overall, the data reveal that huge number of Gram-negative E. coli, P. aeruginosa and K. pneumoniae isolates had co-presence of resistance genes. On the other hand, only $S$. aureus isolates among the Gram-positive bacteria had significant co-presence of resistance genes.

\section{Table 3. Detection of the presence of co-resistance genes in the tested organisms. To determine}

the co-presence of resistance genes, a total of 430 specimens were analyzed by PCR and Sanger sequencing followed by bioinformatics using NCBI blast. Isolates analyzed: $E$. coli $(n=85), P$. aeruginosa $(\mathrm{n}=26)$, K. pneumoniae $(\mathrm{n}=42)$, S. aureus $(\mathrm{n}=84)$, A. baumannii $(\mathrm{n}=20)$ and CNS $(n=28)$.

\begin{tabular}{|c|c|c|c|c|c|c|c|}
\hline $\begin{array}{c}\text { Co-existence } \\
\text { of resistance } \\
\text { genes }\end{array}$ & $\begin{array}{l}E . \\
\text { coli }\end{array}$ & P. aeruginosa & K. pneumoniae & S. aureus & A. baumannii & CNS & $\begin{array}{c}\text { No. of isolates } \\
\text { with co-presence } \\
\text { of resistance } \\
\text { genes }\end{array}$ \\
\hline $\begin{array}{c}\text { CTXM-1, } \\
\text { ErmB }\end{array}$ & 10 & & 4 & 3 & & & 17 \\
\hline $\begin{array}{c}\text { CTXM-1, } \\
\text { ErmC }\end{array}$ & 3 & & & 2 & 1 & & 6 \\
\hline $\begin{array}{c}\text { CTXM-1, } \\
\text { ErmF }\end{array}$ & 3 & 4 & & & & & 7 \\
\hline ErmB, ErmC & 4 & 2 & & & & & 6 \\
\hline ErmB, ErmF & 3 & & & 3 & 1 & & 7 \\
\hline $\begin{array}{c}\text { ErmB, ErmC, } \\
\text { OXA-48 }\end{array}$ & 1 & & & 1 & & & 2 \\
\hline
\end{tabular}




\begin{tabular}{|c|c|c|c|c|c|c|}
\hline $\begin{array}{c}\text { ErmB, OXA- } \\
48\end{array}$ & & 2 & & & & 2 \\
\hline $\begin{array}{l}\text { CTXM-1, } \\
\operatorname{aac}(6)-I b\end{array}$ & 1 & 2 & 4 & 1 & & 8 \\
\hline $\begin{array}{c}\text { CTXM-1, } \\
\text { NDM-1, } \\
\text { aac(3)-II, } \\
\text { ErmB }\end{array}$ & 1 & & & 1 & & 2 \\
\hline $\begin{array}{c}\text { ErmB, ErmF, } \\
\operatorname{aac(6)-Ib}\end{array}$ & 1 & & & & & 1 \\
\hline $\begin{array}{c}\text { ErmB, aac(3)- } \\
\text { II, aph(3)-VI, } \\
\operatorname{aac(6)-Ib}\end{array}$ & & 1 & & & 1 & 2 \\
\hline $\begin{array}{l}\text { ErmB, ErmF, } \\
\operatorname{aac}(6)-I b, \\
\operatorname{ant(3)-I,~} \\
\text { CTXM-1 }\end{array}$ & 1 & & & & & 1 \\
\hline $\begin{array}{c}\text { ErmB, } \\
\text { CTXM-1, } \\
\operatorname{aac}(3)-I I\end{array}$ & 1 & 2 & & & & 3 \\
\hline $\begin{array}{c}\text { ErmF, } \\
\text { CTXM-1, } \\
\text { aac(6)-Ib }\end{array}$ & & & 1 & 1 & & 2 \\
\hline $\begin{array}{l}\text { Aac(6)-Ib, } \\
\operatorname{aac}(3)-I I\end{array}$ & 2 & 1 & 1 & & & 4 \\
\hline $\begin{array}{l}\text { Aac(6)-Ib, } \\
\operatorname{aac}(3)-I I, \\
\text { CTXM-1 }\end{array}$ & 1 & & & 1 & & 2 \\
\hline $\begin{array}{c}\text { OXA-48, } \\
\operatorname{armA}\end{array}$ & & 1 & & & & 1 \\
\hline
\end{tabular}




\begin{tabular}{|c|c|c|c|c|c|c|c|}
\hline $\begin{array}{c}\text { OXA-48, } \\
\operatorname{armA,} \text { aac(6)- } \\
\text { Ib, aac(3)-II }\end{array}$ & & & & 1 & & & 1 \\
\hline $\begin{array}{c}\text { CTXM-1, } \\
\text { NDM-1, OXA- } \\
\text { 48, aac(6)-Ib }\end{array}$ & & 1 & & & & & 1 \\
\hline $\begin{array}{l}\text { CTXM-1, } \\
\text { NDM-1, } \\
\text { aac(6)-Ib }\end{array}$ & & 2 & 2 & & & & 4 \\
\hline $\begin{array}{l}\text { NDM-1, } \\
\operatorname{aac}(3)-I I\end{array}$ & 1 & 1 & & & & & 2 \\
\hline $\begin{array}{l}\text { NDM-1, } \\
\operatorname{aac}(6)-I b\end{array}$ & & & 1 & & & & 1 \\
\hline $\begin{array}{l}\text { Aph(3)-VI, } \\
\text { aac(3)-II, } \\
\text { CTXM-1 }\end{array}$ & & & & 2 & & & 2 \\
\hline $\begin{array}{l}\text { armA, aac(3)- } \\
\text { II, CTXM-1 }\end{array}$ & & & & 1 & & & 1 \\
\hline $\begin{array}{l}\text { CTXM-1, } \\
\operatorname{aac(3)-II~}\end{array}$ & 5 & 4 & & 1 & & & 10 \\
\hline $\begin{array}{l}\text { OXA-48, } \\
\operatorname{aac}(3)-\text {-II }\end{array}$ & & 1 & & 1 & & & 2 \\
\hline $\begin{array}{l}\text { NDM-1, } \\
\operatorname{aac}(3)-I I\end{array}$ & 2 & 2 & & & & 1 & 5 \\
\hline Total & 40 & 26 & 13 & 17 & 2 & 2 & 102 \\
\hline
\end{tabular}
the data are not shown here as co-presence of the tested resistance genes were not detected in these organisms. 


\section{Discussion}

366 The study demonstrates the antibiotic resistance spectrum of the Gram-positive and Gram-negative

367 bacterial isolates from patients with wound infections, acute respiratory infections, diarrhea and

368 typhoid fever. The study also identified the common genes responsible for the resistance of $\beta$ -

369 lactam, macrolide and aminoglycoside class of antibiotics. Although there are reports regarding

370 antibiotic resistance spectrum for Gram-negative bacteria, no previous work provided antibiotic

371 susceptibilty data on Gram-positive bacteria in Bangladesh. Data on genetic basis of antibitic

372 resistance is also limited in Bangladesh. So, the study was undertaken to address this critical

373 knowledge gap. Major focal points of the study included in vitro antibiotic resistance/sensitivity

374 assay for the preserved strains and determination of the (a) spectrum of multidrug resistance and

375 multiple antibiotic resistance (MAR) indices, (b) antibiotic resistance genes, (c) co-presence of

376 multiple antibiotic resistance genes, and (d) kinetics of the rate of spread of resistance over time.

377 Accurate knowledge on these points would help clinicians to avoid unnecessary use of antibiotics,

378 which in turn would help control of rapid spread of antibiotic resistant bacteria. In addition, the

379 data collected from this report would provide an up-to-date overview of the present situation of

380 antibiotic resistance in Bangladesh and the information in turn will assist in fighting the pathogens

381 more effectively.

382 The study found that wound infection alone was associated with 7 of the total 12 pathogens from

383 WHO-enlisted global priority pathogens (GPP) list. Moreover, pathogens from wound infections

384 also yielded high rates of ESBL producers such as E. coli, K. pneumoniae, P. aeruginosa, and $A$.

385 baumannii. This finding is in line with another study performed in Bangladesh [26]. A large

386 number of wound patients including patients with burns are managed in tertiary care hospitals

387 having causality and surgical departments, and burn units. In spite of technological advances that 
have been made in surgery and wound management, wound infections have been regarded as the most common nosocomial infections, especially in patients undergoing surgery [27]. Moreover, in Bangladesh empirical use of antiobiotics without confirming the bacterial identification is a common practice and such practices should be strictly regulated.

With exception of $S$. pneumaniae, Enterococcus spp. and A. baumannii, most of the isolates irrespective of Gram-negative and Gram-positive bacteria exhibited alarming levels of resistance against majority of the available first line of antibiotics. Furthermore, $S$. aureus, K. pneumoniae and $P$. aeruginosa displayed resistance not only against all the first-line of antibiotics but also against most of the second-line antibiotics tested. These findings are in conformity with the findings of multiple resistance genes in the organisms. For example, although $S$. pneumaniae, Enterococcus spp. and A. baumannii had little or no co-presence of resistance genes; $S$. aureus, $K$. pneumoniae and $P$. aeruginosa had higher levels of co-presence of resistance genes and even 100\% of $P$. aeruginosa isolates harbored multiples resistance genes. Such highly resistant organisms may provide a conducive niche for horizonatal transfer of plasmids carrying resistance genes [28], and such a niche may have potential for biofilm formation by the resident bacteria, which in turn may help horizonatal gene transfer [29].

We found that $S$. Typhi isolates were sensitive to several antibiotics, supporting the previous reports $[30,31]$. However, although very few of our $S$. Typhi isolates showed resistance to ciprofloxacin or ceftriaxone, WGS analysis of $S$. Typhi isolates by Tanmoy et al. showed that appearance of local sublineages of $S$. Typhi with acquisition of new genes, such as qnr and blaCTX-M-15 gene in Bangladesh [32] is making $S$. Typhi treatment complicated. Thus, therapeutic failures in typhoid fever management are not rare in the country $[33,34]$. 
Our study revealed that colistin, the last resort antibiotic, was the most active antimicrobial agent against majority of Gram-negative bacteria, although colistin-resistant pathogens including $K$. pneumoniae and $P$. aeruginosa were detected. In addition to colistin, the antibiotics that were being commonly used previously, such as chloramphenicol and trimethoprim-sulfamethoxazole had relatively higher antimicrobial efficacy, which is in consistence with a single-center study in India [12]. These changes are likely due to the replacement of these drugs as an empiric treatment option for infectious diseases with newer drugs such as aminoglycosides, macrolides and $\beta$-lactams. The findings suggest that these drugs can no longer be considered as an empiric treatment option for suspected infections; rather, physicians should rethink to use older drugs again or third-generation cephalosporin. Furthermore, the study showing vancomycin as the strongest antimicrobial against Gram-positive organisms is supported by other studies [35].

Our study revealed CTXM-1 to be the commonest resistance gene (63\%), followed by NDM-1 $(22 \%)$ and OXA-48 (15\%) among the ESBL genes. This is in agreement with a 2013-study conducted in Bangladesh which identified CTXM-1 in 50\% of the cases [36]. This increase in resistance gene frequencies within a short span of duration (5 years) highlights the contribution of CTXM-1 gene in generation of resistance. E. coli was found to be the main reservoir of CTXM1 gene. CTX-M-mediated genes have also extensively detected in wild birds and poultry [37]; and environmental water [13] in Bangladesh. This provides a vicious cycle of such carbapenemaseproducing resistance genes in environment, poultry and human. The finding strengthens the previous report demonstrating CTX-M- producing E. coli as a major cause of both communityonset and hospital-acquired infections in Asian countries, including Korea [38], Taiwan [39], China [40], Hong Kong [41], Japan [42], Malaysia [43], and Thailand [44], and the incidence of serious infections due to CTX-M-producing E. coli likely will continue to increase [45]. $\beta$-lactam 
antibiotics, especially cefotaxime is very frequently used as first line therapy, which is leading to an alarming escalation of CTX-M-mediated resistance.

After CTXM-1, the resistance gene NDM-1 showed an increasing trend between 2015 and 2019. A recent study showed NDM-1 (55\%) as the most prevalent resistance gene in Bangladesh [17]. However, it did not contradict our findings because CTXM-1 was not analyzed in that study. NDM-producing organisms had been reported to be prevalent among Enterobacteriaceae in India and Pakistan, even in community-onset infections and is the most dangerous metallo- $\beta$-lactamase [46]. This scenario of high NDM-1-producing organism in Bangladesh is of great concern because there are very few new antibiotics in the pharmaceutical pipeline that might work effectively against Gram-negative and none of them will be active against NDM-1 producers [47]. Prior studies detected ESBL genes only in the Gram-negative bacteria. However, our study discovered that these resistance genes existed almost equally in the Gram-positive organisms, also. This shift may result from the horizontal gene transfer which is expected to occur vigorously in organisms causing nosocomical infections.

Also, among the macrolide resistance genes, ErmB (55\%) was the most prevalent type. ErmB is mostly associated with azithromycin resistance. In Bangladesh, most diseases such as pneumonia, diarrhea and typhoid are treated with azithromycin, an antibiotic readily available over the counter. The observed frequent detection of ErmB appeared concordant with results from studies reporting ErmB from S. Typhi [15], S. pneumoniae [16] and Shigella sonnei [48]. In a study performed in Bangladesh, Only ErmB was detected among the 7 macrolide resistance genes investigated [15]. Our study could detect the other macrolide resistance genes namely ErmC and ErmF. Moreover, the study detected macrolide resistance genes in $S$. Typhi strains and these findings are of great 
455

456

457

458

459

460

461

462

463

464

465

466

467

468

469

470

471

472

473

474

475

476

concern in Bangladesh where both typhoid and azithromycin are common terms to the physicians $[15]$.

The study also found that MDR isolates harboring antibiotic resistance genes increased during the period between 2015 and 2019. CTXM-1, ErmB, aac(6)-Ib, OXA-48, NDM-1, and aac(3)-II had been the major prevalent resistance genes, which were expected to contribute to the alarminly increased levels of spread of MDR organisms. Other studies also confirmed that the relative proportion of bacteria harboring different antibiotic resistance genes (ARG) was broadly increasing over time and since 1970, there was a 15-fold increase of some resistant bacteria by 2008 [49].

Co-presence of multiple resistance genes is a big concern in the spread of antibiotic resistance. Our study found $23.7 \%$ strains harboring more than one resistance genes, with an $E$. coli isolate possessing 5 resistance genes. Another study identified more than one carbapenemase gene in $45 \%$ of the clinical isolates which had been collected from a hospital in Dhaka [17]. Similarly, an extensively drug resistant Citrobacter freundii isolate was identified from a patient returning from India, which was shown to possess nine $\beta$-lactamase genes including NDM-1, CTX-M-15, OXA1, OXA-9, OXA-10, TEM-1, VIM-4 and CMY genes, and an aminoglycoside resistance gene, namely armA [50]. Another study from our neighboring country, Pakistan found out that majority of NDM-1-producing Enterobacteriaceae co-produced CTX-M-1 and armA-type methylase [51]. These all prove that accumulation of multiple antibiotic resistance genes in the clinical isolates raises an alarm on potential spread of extensively drug-resistant organisms in healthcare settings.

75 Finally, our data showed many antibiotics with little efficacy against disease-specific pathogens that have acquired resistane genes, especially multiple resistance genes. Not only these antibiotics 
477 should be discouraged to use for therapeutic purposes, there should be strict regulation on which

478 antibiotics should be available in the market and which should not be [52, 53]. It is hypothesized

479 that resistant pathogens may shed registance gene(s) without exposure to the antibiotics for a 480 relativey longer period of time and this might be the mechanism for regaining the efficacy by many

481 antibiotics that were in use previously but discontinued due to higher rates of non-susceptilibity.

482 The study had a number of limitations. We analyzed only ESBL, macrolide and aminoglycoside resistance genes. Antibiotic resistance genes, such as genes for tetracyclines, quinolones and other antibiotics should have been investigated for the isolates analyzed as they were found to be resistant on disk diffusion analysis. The reason behind the genotypic discrepancies for some isolates lies in the fact that there might be the presence of other genes or mutations in the resistance genes which were not investigated in the present study. The isolates that remained undetected with the screening recommendations from CLSI are problematic, since failure to detect ESBL, aminoglycoside and macrolide resistance enzymes can have serious consequences for treatment of the patients [54]. In addition, presence of atypical resistance genes in the organisms should have also been investigated. Furthermore, the study depended on disk diffusion method for preliminary resistance assay. It would have been better to determine the minimal inhibitory concentration

493 (MIC) which could reflect resistance condition more accurately. That is, both MIC and disk diffusion assays might reflect true phenotypes. Moreover, it would offer more clearer information on antibiotic resistance if we could expand investigations by including more hospitals, both within 496 the capital city and the broader territories for active surveillance by increasing the sample size. 497 Now-a-days, whole genome sequencing (rWGS) has been popular for such surveillance studies. 498 However, we could not perform WGS because of resource limitations. This is why follow-up 
500 top of that, further research and in-depth analysis are required to find out ways and means to solve

501 global antibiotic resistance problem. The research should also focus on how to facilitate resistance

502 gene shedding and inhibit acquisition of new resistance gene.

503

\section{Conclusion}

505 In summary, highly pathogenic MDR strains were detected from infected patients in tertiary

506 hospitals of the capital of Bangladesh, which can also contribute to other hospital acquired

507 infections. It is to be noted, however, that these observations reflect the overuse and misuse of

508 antibiotics and underscore the need for urgent steps to arrest the increasing incidence of resistance

509 to the antibiotics in the hospital settings. A tailored antibiotic treatment is in demand to tackle this

510 major issue and regular surveillance should be carried out to monitor the susceptibility of these

511 pathogens and choose appropriate regimens both for prophylaxis and treatment of such hazardous

512 infections. 


\section{References}

515 1. Heydarpour F, Rahmani Y, Heydarpour B, Asadmobini A. Nosocomial infections and

516 antibiotic resistance pattern in open-heart surgery patients at Imam Ali Hospital in Kermanshah,

517 Iran. GMS hygiene and infection control. 2017;12.

518 2. Ashiru-Oredope D, Utilization SHobotESPfA, Group RO, Kessel A, Hopkins S, Ashiru-

519 Oredope D, et al. Antimicrobial stewardship: English surveillance programme for antimicrobial

520 utilization and resistance (ESPAUR). Journal of Antimicrobial Chemotherapy.

$521 \quad 2013 ; 68(11): 2421-3$.

522 3. Authority EFS, Prevention ECfD, Control. The European Union summary report on

523 antimicrobial resistance in zoonotic and indicator bacteria from humans, animals and food in

524 2014. EFSA journal. 2016;14(2):4380.

525 4. Frieden T. Antibiotic resistance threats in the United States, 2013. Centers for Disease

526 Control and Prevention, US Department of Health and Human Services. 2013:11-28.

527 5. Laxminarayan R, Duse A, Wattal C, Zaidi AK, Wertheim HF, Sumpradit N, et al.

528 Antibiotic resistance - the need for global solutions. The Lancet infectious diseases.

$529 \quad 2013 ; 13(12): 1057-98$.

530 6. Islam S, Aldstadt J, Aga D. Global antimicrobial resistance: a complex and dire threat

531 with few definite answers. Tropical Medicine \& International Health. 2019;24(6):658-62.

532 7. Ahmad M, Khan AU. Global economic impact of antibiotic resistance: a review. Journal 533 of global antimicrobial resistance. 2019.

534 8. Gandra S, Barter D, Laxminarayan R. Economic burden of antibiotic resistance: how 535 much do we really know? Clinical microbiology and infection. 2014;20(10):973-80. 
536 9. Ahmed I, Rabbi MB, Sultana S. Antibiotic resistance in Bangladesh: A systematic

537 review. International Journal of Infectious Diseases. 2019;80:54-61.

538 10. Shibl A, Memish Z, Osoba A. Antibiotic resistance in developing countries. Journal of 539 chemotherapy. 2001;13(sup1):40-4.

540 11. Organization WH. Monitoring global progress on addressing antimicrobial resistance:

541 analysis report of the second round of results of AMR country self-assessment survey 2018.

5422018.

543 12. Gandra S, Mojica N, Klein EY, Ashok A, Nerurkar V, Kumari M, et al. Trends in

544 antibiotic resistance among major bacterial pathogens isolated from blood cultures tested at a

545 large private laboratory network in India, 2008-2014. International Journal of Infectious

546 Diseases. 2016;50:75-82.

547 13. Toleman MA, Bugert JJ, Nizam SA. Extensively drug-resistant New Delhi metallo- $\beta$ -

548 lactamase-encoding bacteria in the environment, Dhaka, Bangladesh, 2012. Emerging infectious 549 diseases. 2015;21(6):1027.

550 14. Islam TAB, Shamsuzzaman S, Farzana A. Prevalence and antibiogram of ESBL

551 producing Gram-negative bacilli isolated from urine in Dhaka Medical College Hospital,

552 Bangladesh. Bangladesh Journal of Medical Microbiology. 2015;9(1):17-21.

553 15. Ahsan S, Rahman S. Azithromycin resistance in clinical isolates of Salmonella enterica

554 serovars Typhi and paratyphi in Bangladesh. Microbial Drug Resistance. 2019;25(1):8-13.

555 16. Hasanuzzaman M, Malaker R, Islam M, Baqui AH, Darmstadt GL, Whitney CG, et al.

556 Detection of macrolide resistance genes in culture-negative specimens from Bangladeshi

557 children with invasive pneumococcal diseases. Journal of global antimicrobial resistance.

$558 \quad 2017 ; 8: 131-4$ 
559 17. Begum N, Shamsuzzaman S. Emergence of carbapenemase-producing urinary isolates at

560 a tertiary care hospital in Dhaka, Bangladesh. Tzu Chi Medical Journal. 2016;28(3):94-8.

561 18. Ahmed D, Ud-Din AIMS, Wahid SUH, Mazumder R, Nahar K, Hossain A. Emergence

562 of bla TEM Type Extended-Spectrum $\beta$-Lactamase Producing Salmonella spp. in the Urban Area

563 of Bangladesh. ISRN microbiology. 2014;2014.

564 19. Boyce J. MRSA patients: proven methods to treat colonization and infection. Journal of 565 Hospital Infection. 2001;48:S9-S14.

566 20. Sugandhi P, Prasanth DA. Bacteriological profile of diabetic foot infections. Int J Innov 567 Res Sci Eng Technol. 2014;3.

568 21. Bogaert D, de Groot R, Hermans P. Streptococcus pneumoniae colonisation: the key to 569 pneumococcal disease. The Lancet infectious diseases. 2004;4(3):144-54.

570 22. Collee JG, Miles R, Watt B. Tests for identification of bacteria. Mackie and McCartney 571 practical medical microbiology. 1996;14:131-49.

572 23. Magiorakos AP, Srinivasan A, Carey R, Carmeli Y, Falagas M, Giske C, et al.

573 Multidrug-resistant, extensively drug-resistant and pandrug-resistant bacteria: an international 574 expert proposal for interim standard definitions for acquired resistance. Clinical microbiology 575 and infection. 2012;18(3):268-81.

576 24. Krumperman PH. Multiple antibiotic resistance indexing of Escherichia coli to identify 577 high-risk sources of fecal contamination of foods. Appl Environ Microbiol. 1983;46(1):165-70. 578 25. Dashti AA, Jadaon MM, Abdulsamad AM, Dashti HM. Heat treatment of bacteria: a 579 simple method of DNA extraction for molecular techniques. Kuwait Med J. 2009;41(2):117-22.

580 26. Jobayer M, Afroz Z, Nahar SS, Begum A, Begum SA, Shamsuzzaman S. Antimicrobial 581 susceptibility pattern of extended-spectrum beta-lactamases producing organisms isolated in a 
582 tertiary care hospital, Bangladesh. International Journal of Applied and Basic Medical Research. $583 \quad 2017 ; 7(3): 189$.

584 27. Ahmed MI. Prevalence of nosocomial wound infection among postoperative patients and 585 antibiotics patterns at teaching hospital in Sudan. North American journal of medical sciences. $586 \quad 2012 ; 4(1): 29$.

587 28. Komijani M, Bouzari M, Rahimi F. Detection and characterization of a novel lytic 588 bacteriophage (vB-KpneM-Isf48) against Klebsiella pneumoniae isolates from infected wounds 589 carrying antibiotic-resistance genes (TEM, SHV, and CTX-M). 2017.

590 29. Madsen JS, Burmølle M, Hansen LH, Sørensen SJ. The interconnection between biofilm 591 formation and horizontal gene transfer. FEMS Immunology \& Medical Microbiology.

$592 \quad 2012 ; 65(2): 183-95$.

593 30. Menezes GA, Harish BN, Khan MA, Goessens W, Hays J. Antimicrobial resistance 594 trends in blood culture positive Salmonella Typhi isolates from Pondicherry, India, 2005-2009. 595 Clinical Microbiology and Infection. 2012;18(3):239-45.

596 31. Madhulika U, Harish B, Parija S. Current pattern in antimicrobial susceptibility of 597 Salmonella Typhi isolates in Pondicherry. Indian Journal of Medical Research. 2004;120(2):111.

598 32. Tanmoy AM, Westeel E, De Bruyne K, Goris J, Rajoharison A, Sajib MS, et al.

599 Salmonella enterica Serovar Typhi in Bangladesh: exploration of genomic diversity and 600 antimicrobial resistance. MBio. 2018;9(6):e02112-18.

601 33. Saha SK, Darmstadt GL, Baqui AH, Crook DW, Islam MN, Islam M, et al. Molecular 602 basis of resistance displayed by highly ciprofloxacin-resistant Salmonella enterica serovar Typhi 603 in Bangladesh. Journal of clinical microbiology. 2006;44(10):3811-3. 
604

605

606

607

608

609

610

611

612

613

614

615

616

617

618

619

620

621

622

623

624

625

626
34. Ahmed D, D'Costa LT, Alam K, Nair GB, Hossain MA. Multidrug-resistant Salmonella enterica serovar typhi isolates with high-level resistance to ciprofloxacin in Dhaka, Bangladesh. Antimicrobial agents and chemotherapy. 2006;50(10):3516-7.

35. Ghadiri H, Vaez H, Khosravi S, Soleymani E. The antibiotic resistance profiles of bacterial strains isolated from patients with hospital-acquired bloodstream and urinary tract infections. Critical care research and practice. 2012;2012.

36. Islam SS, Malek MA, Haque AF, Talukder KA, Akhter MZ. Beta lactamase genes of extended spectrum beta lactamase producing Escherichia coli from anorectal sepsis cases in Bangladesh. Bangladesh Journal of Microbiology. 2013;30(1-2):23-9.

37. Hasan B, Sandegren L, Melhus Å, Drobni M, Hernandez J, Waldenström J, et al. Antimicrobial drug-resistant Escherichia coli in wild birds and free-range poultry, Bangladesh. Emerging infectious diseases. 2012;18(12):2055.

38. Park SH, Byun J-H, Choi S-M, Lee D-G, Kim S-H, Kwon J-C, et al. Molecular epidemiology of extended-spectrum $\beta$-lactamase-producing Escherichia coli in the community and hospital in Korea: emergence of ST131 producing CTX-M-15. BMC infectious diseases. 2012;12(1):149.

39. Chung H-C, Lai C-H, Lin J-N, Huang C-K, Liang S-H, Chen W-F, et al. Bacteremia caused by extended-spectrum- $\beta$-lactamase-producing Escherichia coli sequence type ST131 and non-ST131 clones: comparison of demographic data, clinical features, and mortality.

Antimicrobial agents and chemotherapy. 2012;56(2):618-22.

40. Cao X, Cavaco LM, Lv Y, Li Y, Zheng B, Wang P, et al. Molecular characterization and antimicrobial susceptibility testing of Escherichia coli isolates from patients with urinary tract infections in 20 Chinese hospitals. Journal of clinical microbiology. 2011;49(7):2496-501. 
627 41. Ho P-L, Lo WU, Lai EL, Chow K-H, Yam W-C. Escherichia coli O25b-ST131 is an 628 important cause of antimicrobial-resistant infections in women with uncomplicated cystitis.

629 Journal of antimicrobial chemotherapy. 2012;67(10):2534-5.

630 42. Matsumura Y, Yamamoto M, Nagao M, Hotta G, Matsushima A, Ito Y, et al. Emergence

631 and spread of B2-ST131-O25b, B2-ST131-O16 and D-ST405 clonal groups among extended-

632 spectrum- $\beta$-lactamase-producing Escherichia coli in Japan. Journal of antimicrobial

633 chemotherapy. 2012;67(11):2612-20.

634 43. Ho WS, Balan G, Puthucheary S, Kong BH, Lim KT, Tan LK, et al. Prevalence and

635 characterization of multidrug-resistant and extended-spectrum beta-lactamase-producing

636 Escherichia coli from pediatric wards of a Malaysian hospital. Microbial Drug Resistance.

$637 \quad 2012 ; 18(4): 408-16$.

638 44. Kiratisin P, Apisarnthanarak A, Laesripa C, Saifon P. Molecular characterization and 639 epidemiology of extended-spectrum- $\beta$-lactamase-producing Escherichia coli and Klebsiella 640 pneumoniae isolates causing health care-associated infection in Thailand, where the CTX-M

641 family is endemic. Antimicrobial agents and chemotherapy. 2008;52(8):2818-24.

642 45. Rashid MM, Chisti MJ, Akter D, Sarkar M, Chowdhury F. Antibiotic use for pneumonia 643 among children under-five at a pediatric hospital in Dhaka city, Bangladesh. Patient preference 644 and adherence. 2017;11:1335.

645 46. Kumarasamy KK, Toleman MA, Walsh TR, Bagaria J, Butt F, Balakrishnan R, et al.

646 Emergence of a new antibiotic resistance mechanism in India, Pakistan, and the UK: a

647 molecular, biological, and epidemiological study. The Lancet infectious diseases.

$648 \quad 2010 ; 10(9): 597-602$. 
649 47. Livermore DM. Has the era of untreatable infections arrived? Journal of Antimicrobial 650 Chemotherapy. 2009;64(suppl_1):i29-i36.

651 48. Rahman M, Haque A, Deeba IM, Ahmed D, Zahidi T, Rimu AH, et al. Emergence of 652 extensively drug-resistant Shigella sonnei in Bangladesh. Immunol Infect Dis. 2017;5:1-9.

653 49. Knapp CW, Dolfing J, Ehlert PA, Graham DW. Evidence of increasing antibiotic 654 resistance gene abundances in archived soils since 1940. Environmental science \& technology. $6552010 ; 44(2): 580-7$.

656 50. Poirel L, Ros A, Carricajo A, Berthelot P, Pozzetto B, Bernabeu S, et al. Extremely drug657 resistant Citrobacter freundii isolate producing NDM-1 and other carbapenemases identified in a 658 patient returning from India. Antimicrobial agents and chemotherapy. 2011;55(1):447-8.

659 51. Day KM, Ali S, Mirza IA, Sidjabat HE, Silvey A, Lanyon CV, et al. Prevalence and 660 molecular characterization of Enterobacteriaceae producing NDM-1 carbapenemase at a military 661 hospital in Pakistan and evaluation of two chromogenic media. Diagnostic microbiology and 662 infectious disease. 2013;75(2):187-91.

663 52. Garau J, Nicolau DP, Wullt B, Bassetti M. Antibiotic stewardship challenges in the 664 management of community-acquired infections for prevention of escalating antibiotic resistance. 665 Journal of global antimicrobial resistance. 2014;2(4):245-53.

666 53. Lawes T, Lopez-Lozano J-M, Nebot CA, Macartney G, Subbarao-Sharma R, Dare CR, et 667 al. Effects of national antibiotic stewardship and infection control strategies on hospital668 associated and community-associated meticillin-resistant Staphylococcus aureus infections 669 across a region of Scotland: a non-linear time-series study. The Lancet Infectious Diseases. $670 \quad 2015 ; 15(12): 1438-49$. 
671 54. Nyberg SD, Österblad M, Hakanen AJ, Huovinen P, Jalava J, Resistance FSGfA.

672 Detection and molecular genetics of extended-spectrum beta-lactamases among cefuroxime-

673 resistant Escherichia coli and Klebsiella spp. isolates from Finland, 2002-2004. Scandinavian

674 journal of infectious diseases. 2007;39(5):417-24.

675 
A

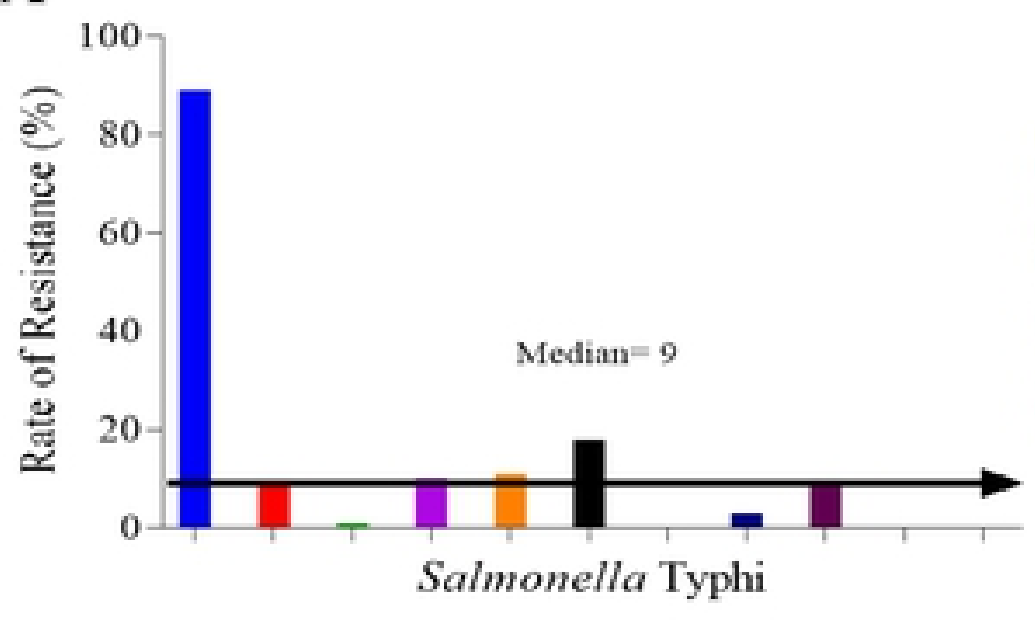

C

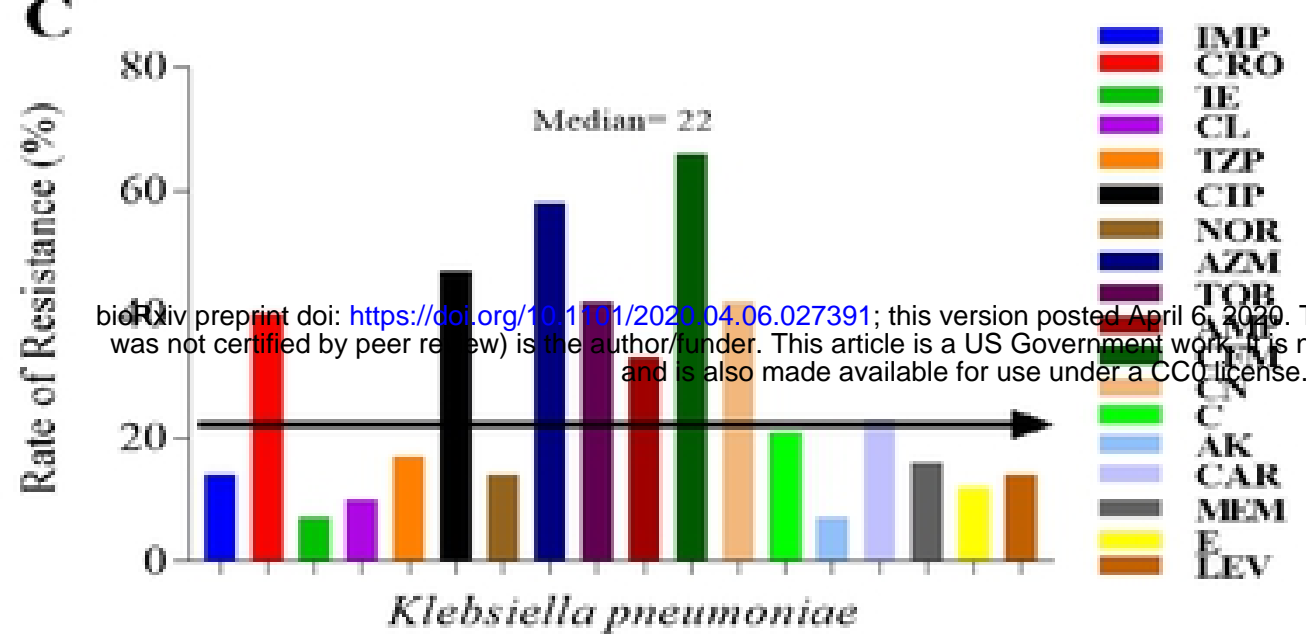

E

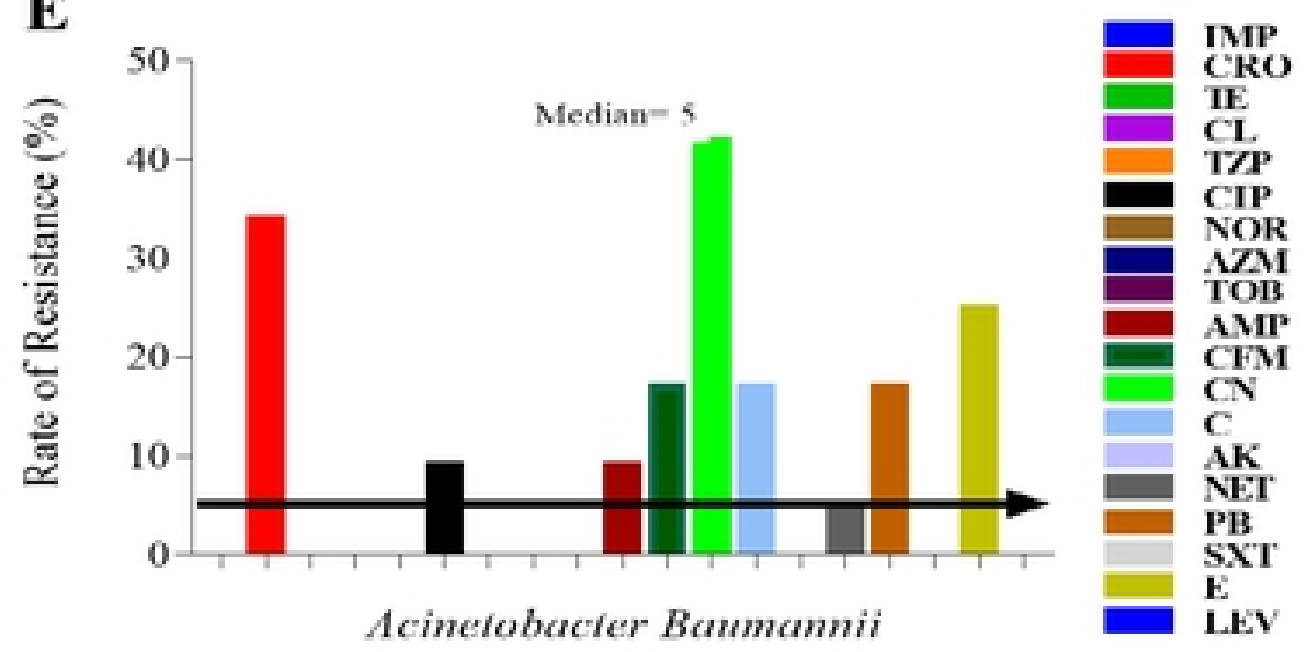

G

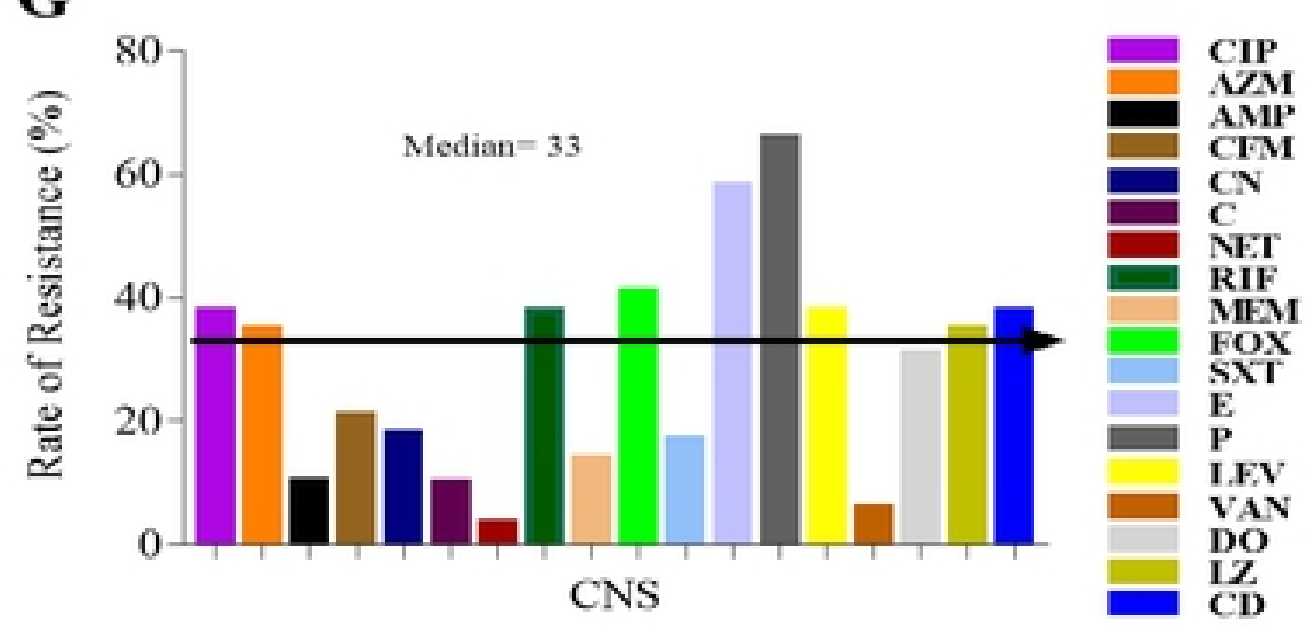

B

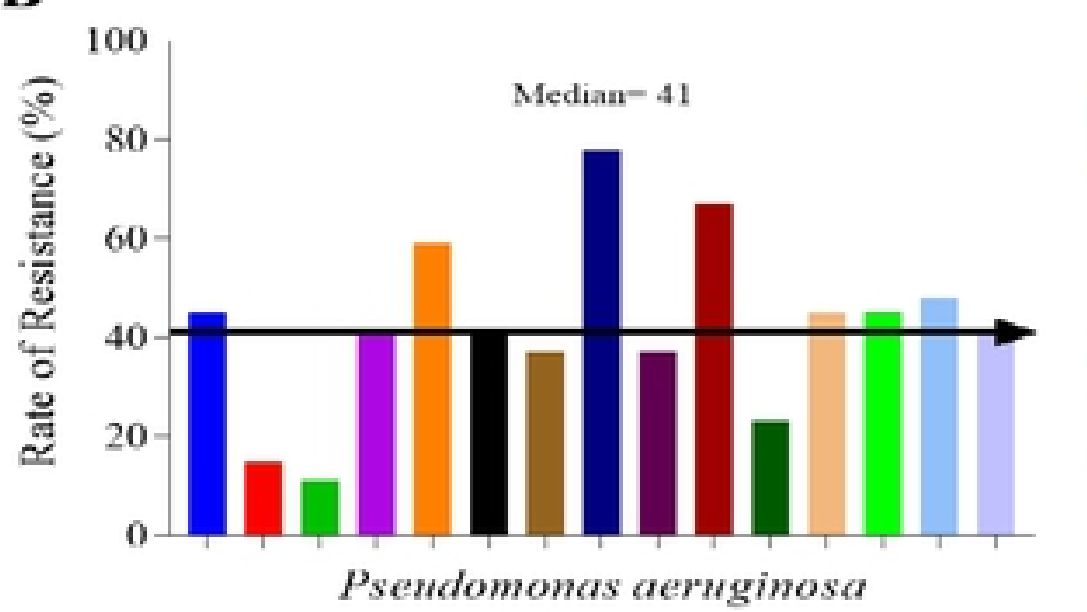

D

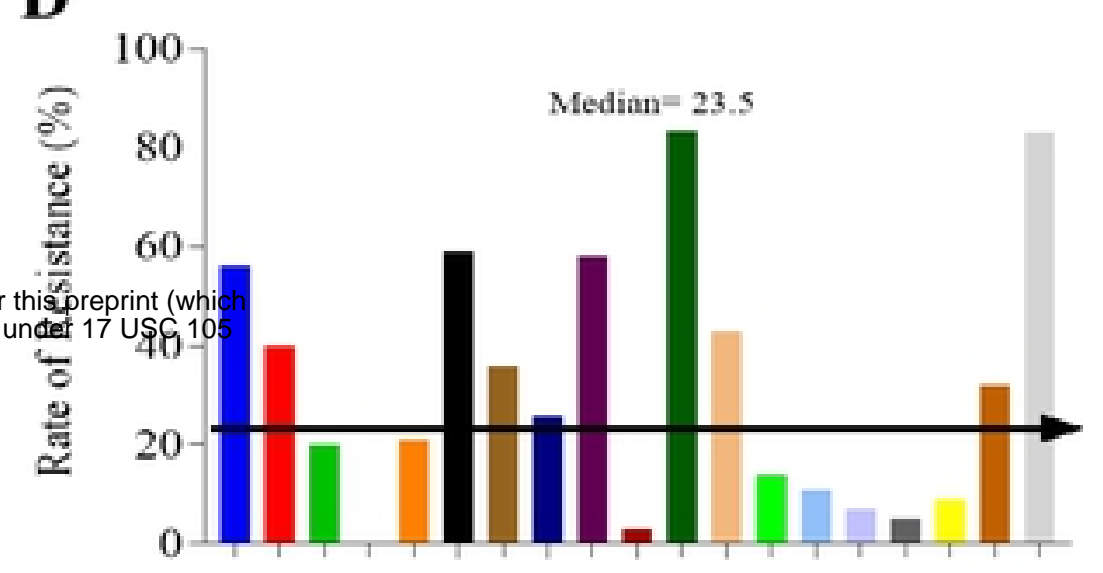

Escherichia coli

F

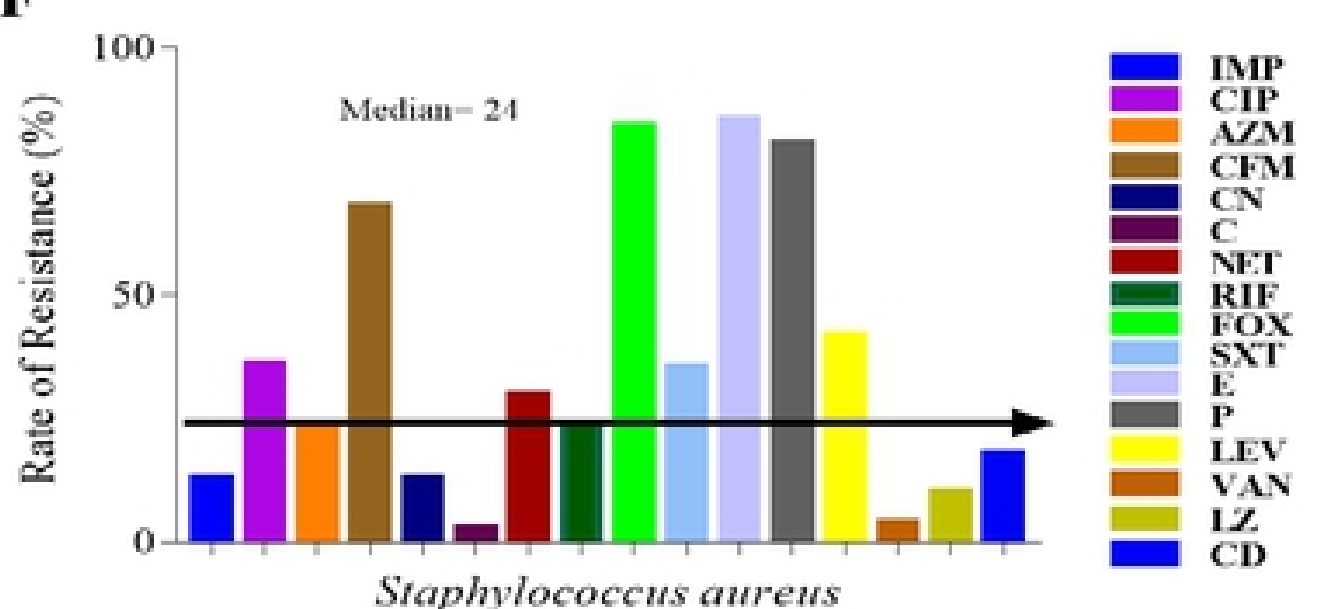

H

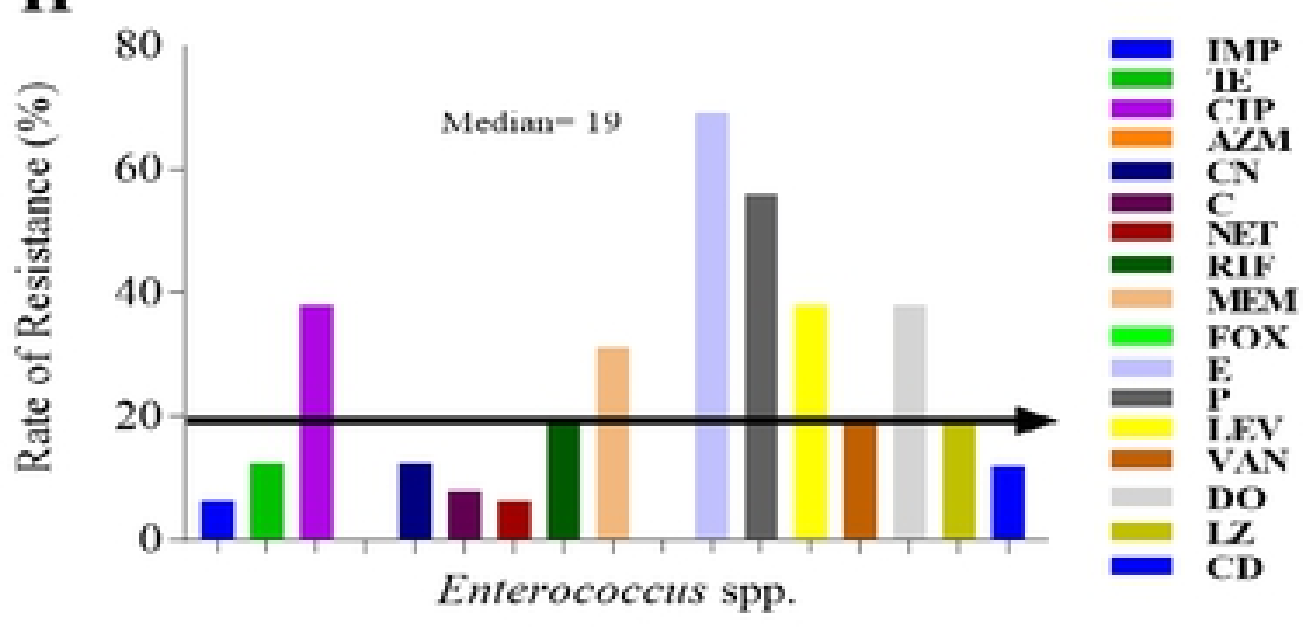

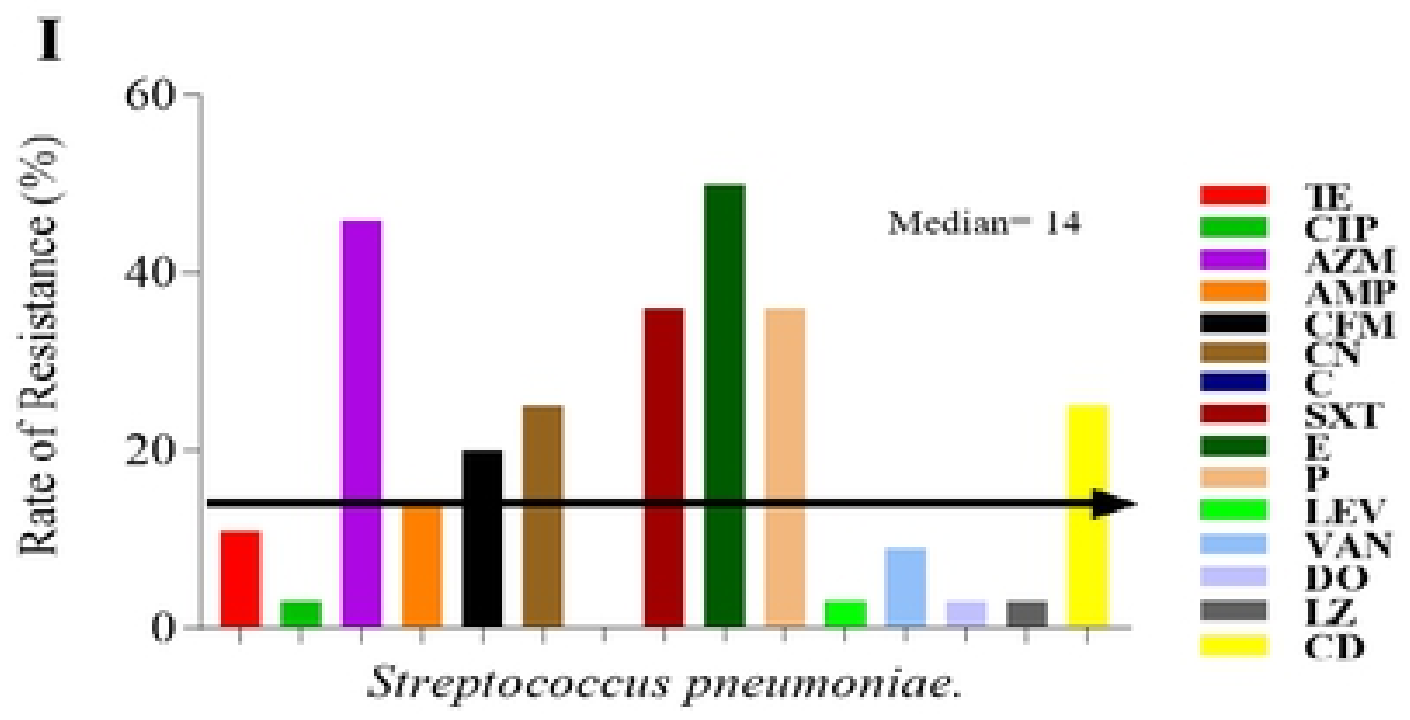

Fig 1. Rates of resistance of the isolated organisms to different a 
bioRxiv preprint ddi:(AtAs://doi.org/10.1101/2020.04.06.027391; this version posted April 6, 2020. The copyright holder for this preprint (which was not certified by peer review) is the author/funder. This article is a US Government work. It is not subject to copyright under 17 USC 105

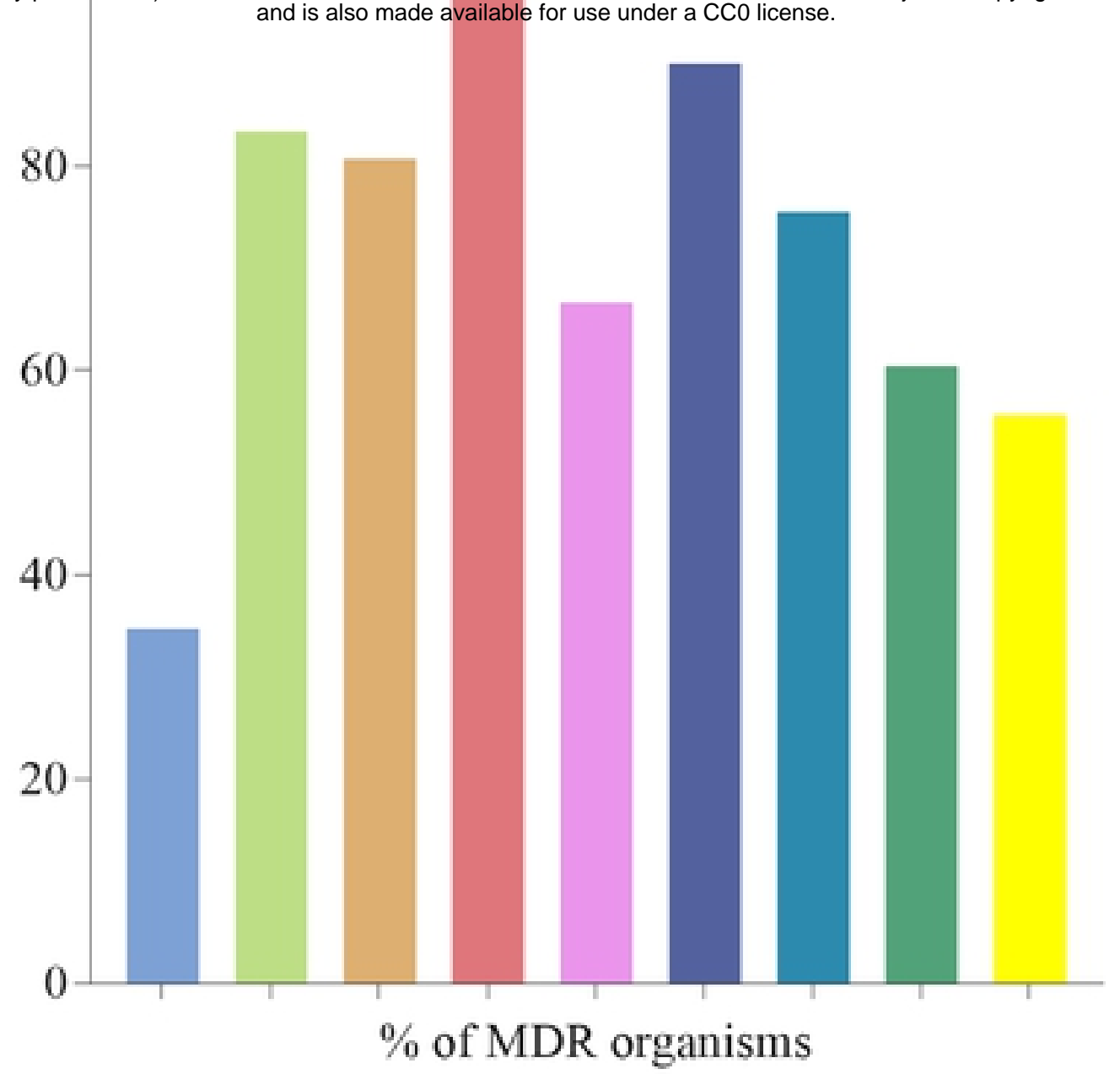

- Salmonella Typhi

- Pseudomonas aeruginosa

- Klebsiella pneumoniae

- Escherichia coli

- Acinetobacter baumannii

- Staphylococcus aureus

Enterococcus spp.

CNS

- Streptococcus pneumoniae

B

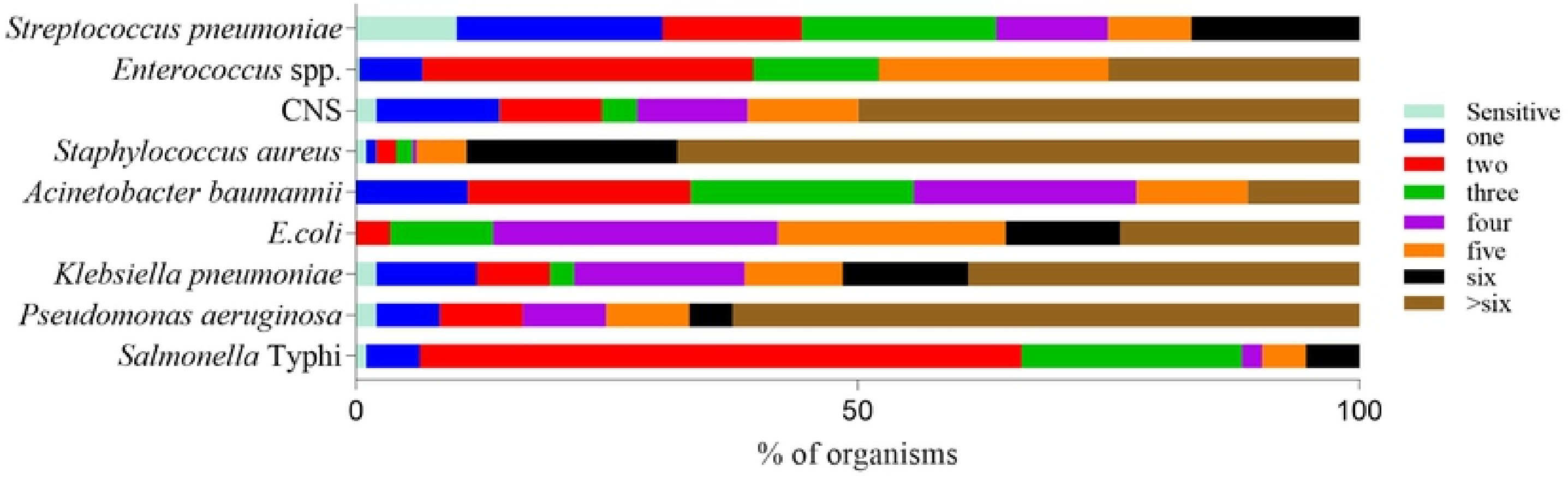

Fig 2. Resistance frequency of the indicated clinical isolates. 


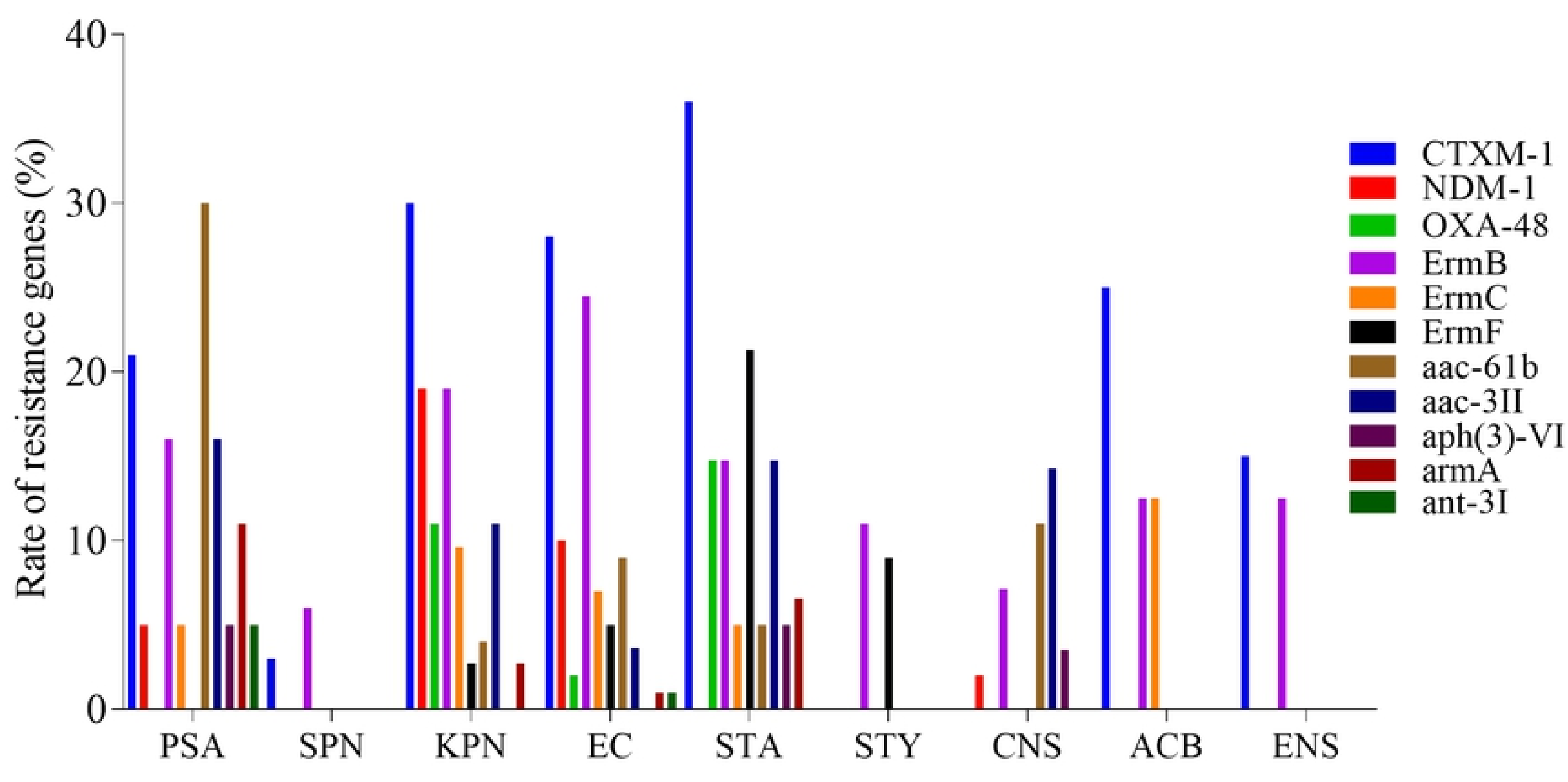

Fig 3. Distribution of CTXM-1, NDM-1, OXA-48, ErmB, ErmF, ErmC 


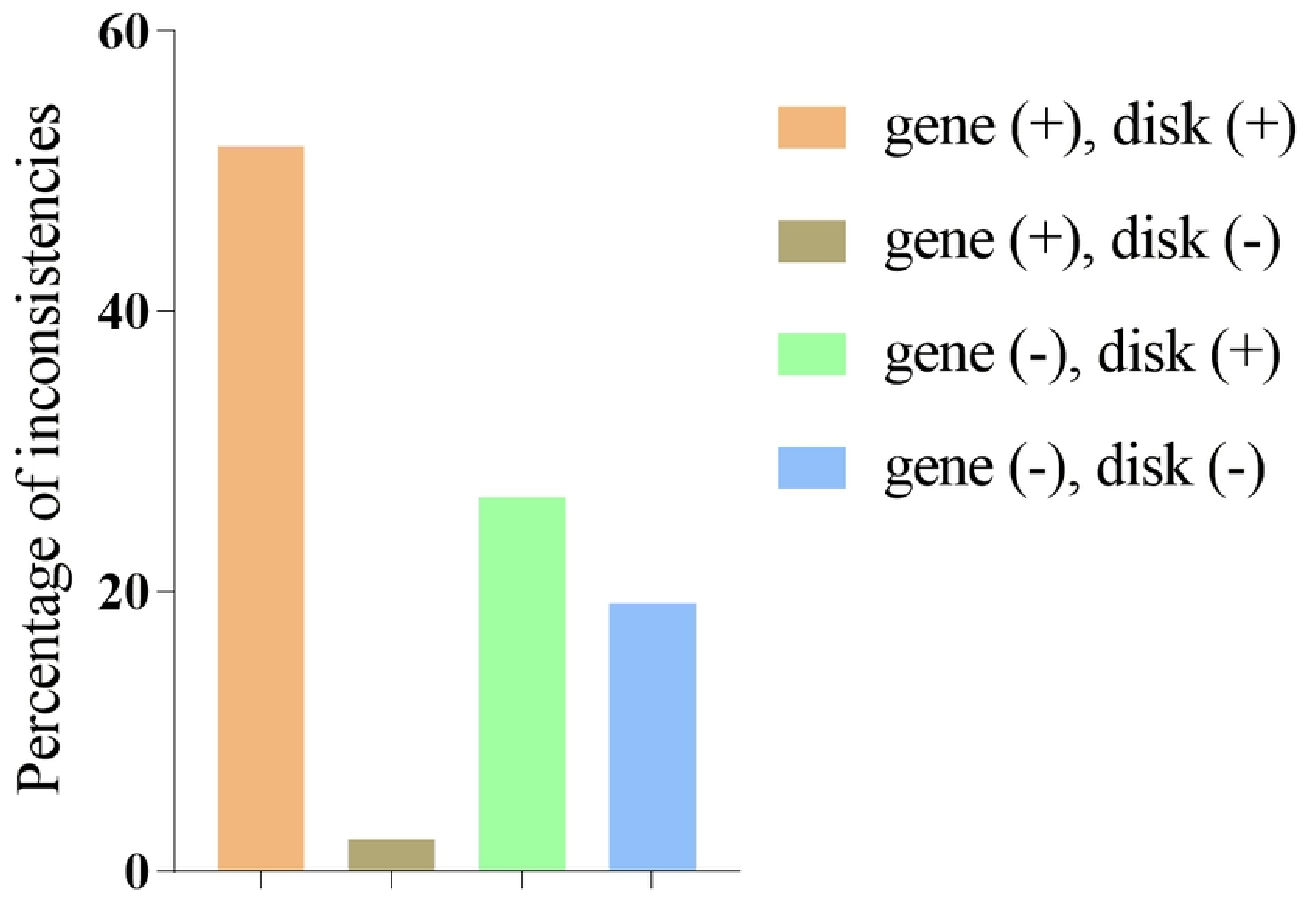

Fig 4. Existing inconsistencies among the isolated organisms. 

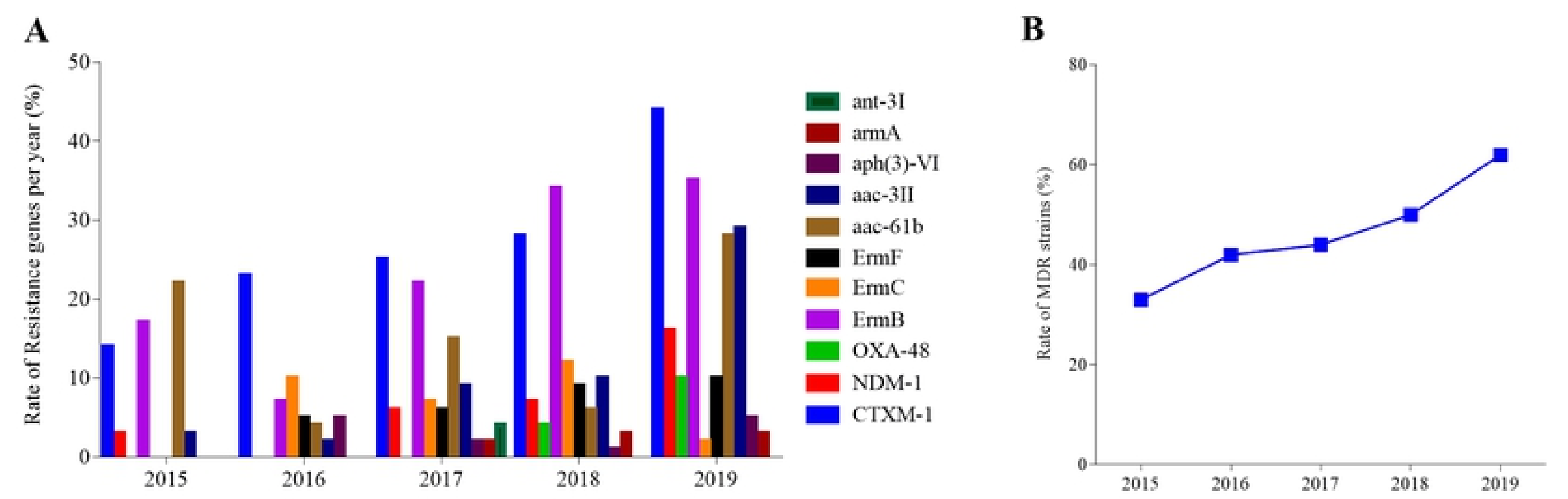

Fig 5. Kinetics of the spread of MDR organisms along with antibi 